\title{
Full-Scale Use of Microwave Heating in Construction of Longitudinal Joints and Crack Healing in Asphalt Pavements
}

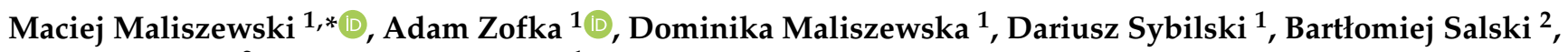 \\ Tomasz Karpisz ${ }^{2}$ and Rafał Rembelski ${ }^{1}$ \\ 1 Pavement Technology Division, Road and Bridge Research Institute, 03-302 Warsaw, Poland; \\ azofka@ibdim.edu.pl (A.Z.); dmaliszewska@ibdim.edu.pl (D.M.); d.sybilski@ibdim.edu.pl (D.S.); \\ rrembelski@ibdim.edu.pl (R.R.) \\ 2 The Institute of Radioelectronics and Multimedia Technology, The Faculty of Electronics and Information \\ Technology, Warsaw Technical University, 00-665 Warsaw, Poland; bsalski@ire.pw.edu.pl (B.S.); \\ tkarpisz@ire.pw.edu.pl (T.K.) \\ * Correspondence: mmaliszewski@ibdim.edu.pl
}

Citation: Maliszewski, M.; Zofka, A.; Maliszewska, D.; Sybilski, D.; Salski,

B.; Karpisz, T.; Rembelski, R.

Full-Scale Use of Microwave Heating in Construction of Longitudinal Joints and Crack Healing in Asphalt Pavements. Materials 2021, 14, 5159. https://doi.org/10.3390/ma14185159

Academic Editors: Juan Gallego Medina and Miguel A. Franesqui

Received: 28 July 2021

Accepted: 2 September 2021

Published: 8 September 2021

Publisher's Note: MDPI stays neutral with regard to jurisdictional claims in published maps and institutional affiliations.

Copyright: (c) 2021 by the authors. Licensee MDPI, Basel, Switzerland. This article is an open access article distributed under the terms and conditions of the Creative Commons Attribution (CC BY) license (https:/ / creativecommons.org/licenses/by/ $4.0 /)$.

\begin{abstract}
Asphalt pavement construction technology is an industry branch that undergoes constant development. Analyzing the directions of the development, one can divide it into two mainstreams: the development of roadworks equipment and the development of roadworks technology. Microwave heating technique has been mentioned in the road industry from the early '70s, but research records from practical full-scale use are very rare. This article presents the evaluation of the possible use of microwave heating technique during a particular aspect of the construction process, namely, the formation of longitudinal joints and the potential repair process of the cracked asphalt pavement. Research results showed that joints constructed using microwave-assisted heating performed the same or even better with regards to tensile characteristics comparing to other techniques. Also, the highest level of compaction was reached among the other tested techniques applied to the wearing course level. The second part of the research experiment showed the large potential of the microwave crack healing technique. The asphalt pavement was healed on its full depth of $10 \mathrm{~cm}$ with the single healing operation applied. Although some limitations may occur in the practical use of microwave heating, the test results suggest that it is a very promising technique and should be further developed (for, e.g., shielding concerns, electricity supply). The microwave heating technique is powered with electricity, which is important when there is a constant need for further reductions of $\mathrm{CO}_{2}$ emissions. It can be reached in parallel with clean energy or clean electricity sources.
\end{abstract}

Keywords: asphalt mix; longitudinal joints; microwave heating; dielectric heating; mechanical properties; physical properties; asphalt pavement; self-healing; asphalt pavement repair; crackshealing

\section{Introduction}

Proper paving of the asphalt layer is a very complex process requiring controlling and synchronizing of many separate processes to gain successful and durable effect. Three main processes in the paving of asphalt layer can be addressed, i.e., preparation of durable and bearable subgrade for paving asphalt layer, hot mix asphalt production and transport, and forming of asphalt layers and compaction. One of the inevitable stages of the laying and compaction process is the formation of longitudinal and transversal joints. Laying of the monolith, a seamless asphalt layer with no vertical discontinuities, would be the most desirable method, but it is not possible in 75\% of cases [1]. Unfortunately, it requires formation of the joints or wedges that are of worse quality in terms of pavement properties than monolith multilayered structure [2]. Because the pavement joint area is usually characterized by a lowered compaction degree, asphalt mix segregation or discontinuity, it is vulnerable to premature deterioration. Thus, the joint area in typical, dense graded 
asphalt pavement is susceptible to premature cracking [3] or aggregates evacuation caused by factors including water impact, freeze and thaw cycles or bitumen aging [4,5]. After the formation of discontinuity, a repair process is needed. In the case of asphalt pavements, the repair is usually done using hot-applied joint sealants or cold-applied joint sealants and materials [6].

There are several classical methods of constructing longitudinal joints. A brief review of pavement longitudinal joint-forming technology together with the pros and cons was presented in Table $1[7,8]$.

Table 1. Main groups of pavement longitudinal joints forming technologies.

\begin{tabular}{|c|c|c|c|}
\hline Technology Group & Brief Description & Advantages & Disadvantages \\
\hline $\begin{array}{l}\text { Seamless asphalt } \\
\text { paving }\end{array}$ & $\begin{array}{c}\text { A single paver lays a } \\
\text { single layer }\end{array}$ & $\begin{array}{l}\text { Seamless technology, no } \\
\text { discontinuities, no compaction issues }\end{array}$ & Limited by a width of a paver \\
\hline $\begin{array}{l}\text { Hot by hot (echelon } \\
\text { paving) }\end{array}$ & $\begin{array}{l}\text { More than one paver lays } \\
\text { more than one layer; } \\
\text { pavers work side-by-side } \\
\text { and overlap }\end{array}$ & $\begin{array}{c}\text { Joints are formed in hot material, the } \\
\text { best possible adhesion between layers } \\
\text { and compaction within the joint area } \\
\text { is kept }\end{array}$ & $\begin{array}{c}\text { Difficulties with paving } \\
\text { synchronization, compaction } \\
\text { order and homogeneity; multiple } \\
\text { sets of paving and compacting } \\
\text { equipment needed }\end{array}$ \\
\hline Hot by cold & $\begin{array}{l}\text { Paver lays asphalt layer } \\
\text { and after cooling down } \\
\text { the next layer is paved }\end{array}$ & $\begin{array}{l}\text { Work can be staged; different } \\
\text { solutions for joints forming are } \\
\text { available, using standard equipment, } \\
\text { special equipment or special } \\
\text { sealing materials }\end{array}$ & $\begin{array}{l}\text { Seams are formed between hot } \\
\text { and cold asphalt mix, not } \\
\text { optimum adhesion conditions are } \\
\text { achieved; mistakes in } \\
\text { joint-forming process are frequent; } \\
\text { additional material is used }\end{array}$ \\
\hline
\end{tabular}

Proper strategy and technology of asphalt layer paving should ensure good quality of longitudinal joints and minimize the potential of discontinuity. As the seamless jointforming technique is unlikely to be used in most cases, "hot by cold" technology must be used. Cold layer, namely, its edge to which next layer will be paved, must be properly prepared before laying next hot mix layer. There are several ways to prepare the so-called "cold edge". There are forming techniques, sealing techniques and heating techniques. The first group briefly consists of the following:

- skewed profiling $\left(60^{\circ}\right)$, formed by the roller compactor (or paver) equipped with the edge forming plate,

- $\quad$ vertical profiling, formed with the use of knife installed on roller compactor; formed after compaction of asphalt layer when it cools down below compaction temperature,

- different wedge compactors for forming the longitudinal joints,

- a different strategy of asphalt paving and compaction order, in particular, the following:

- use of adequate thickness of asphalt layer, which cannot be thinner than cold lane after compaction, because it may lead to under compaction issue,

- use of the paver controlled with an averaging ski, helping to synchronize layers thickness,

- establishing of steel or rubber roller compactor passes over the joint,

- the finish of compaction work before reaching layer minimum compaction temperature.

Second group, the use of additional sealing material, is also very popular in Polish road construction practice. The following materials can be used:

- additional tack-coat application over the cold lane edge (asphalt emulsion, hot asphalt or bituminous paste),

- additional sealing material, e.g., bituminous tape, bituminous paste or bituminous sealant. 
The last group is still not popular in Polish road engineering. The construction of longitudinal joints with the following techniques is possible:

- reheating of cold lane edge before or after application of hot layer using infrared heaters $[9,10]$,

- reheating of cold lane edge using induction heating [11],

- reheating of cold lane edge using microwave applicator.

Akpir [12] names particular problems occurring during the formation of joints: low compaction, irregularity and segregation of aggregate. These problems induce locally increased water permeability of the structure, thus decreasing water and frost resistance. While some of the technologies are bringing promising results, e.g., infrared heating technology can help increasing compaction ratio, some authors claim that microwave heating potentially could improve properties of the joint [13]. IBDiM and the industry partner QWED sp. z o.o. finished a project named NGAM2, cofounded by the Polish National Center for Research and Development [NCBR, grant no. PBS2/B3/19/2013]. One of the main aims of this project was to evaluate the possibility and assess the effectiveness of the use of microwave technology to improve the quality of road works. Basing on the project results, the PhD thesis and monography was published [14]. This article focuses on the research concerning hot by a cold joint-forming technique using a standard untreated technique (vertical and skewed joint), additional material sealing as well as additional joint treatment.

Microwave heating (also known as dielectric heating) fundamentals are described using theory formulated by Maxwell [15], which has been described using differential equations $[16,17]$ and is well defined in the literature, e.g. [18]. The dielectric heating uses energy transfer in contrast to traditional heating, which only uses the heat transfer by radiation, convection or conduction. Dielectric heating is of volumetric type and thus achieves higher heating rates than conventional convection or conduction heating, giving overall reduction of overall processing time $[19,20]$. But there are some restraints in using dielectric heating, which come from dielectric properties of materials. Not all media are capable of being heated dielectrically, as some of them are transparent to dielectric heating. The dielectric constant $\varepsilon^{\prime}$, loss tangent tan $\delta$ and dielectric loss $\varepsilon^{\prime \prime}$ are the parameters that describe capabilities of media to be dielectrically heated. The ideological scheme of dielectric heating of hot-mix asphalt is presented in Figure 1.

Regarding asphalt pavements, one of the asphalt constituent materials, the bitumen is almost invisible to dielectric heating while the main constituent, the aggregate, is dielectrically heatable [21]. Aggregates typically used in asphalt production are of a different mineral composition resulting from the locally available rock material. There is a growing number of research articles devoted to microwave heating of pure asphalt mixes. Researchers have tested the microwave heating influence on asphalt properties [22-24], the possibility of assisting the recycling process $[21,25,26]$, the possibility of asphalt mix selfhealing [27-29] or healing [30,31]. Other researchers are modeling the heating influence and healing potential of microwaves or induction heating on asphalt mix properties [32,33]. Recent research is directed on the use of special aggregates or steel slags [34-37], modified bitumen [38] or additives and admixes [39-41], which help to improve the asphalt dielectric heating ability or healing potential [42].

In this study, there were no extra constituent materials added nor applied, and asphalt mixes were formulated using the typical aggregate available on the Polish market. Presented test results are not focused on the properties of the asphalt itself but the performancerelated properties of asphalt longitudinal joints. In addition the full-scale, crack repair was evaluated as well. 
(a)

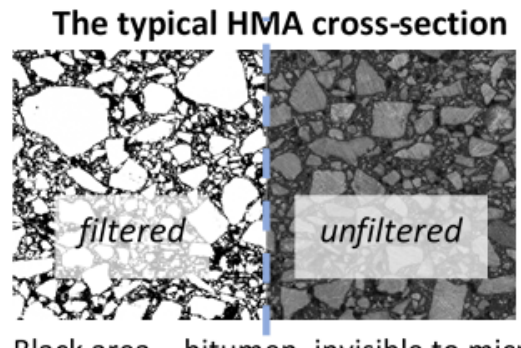

Black area - bitumen, invisible to microwaves

White area - aggregate, lossy media

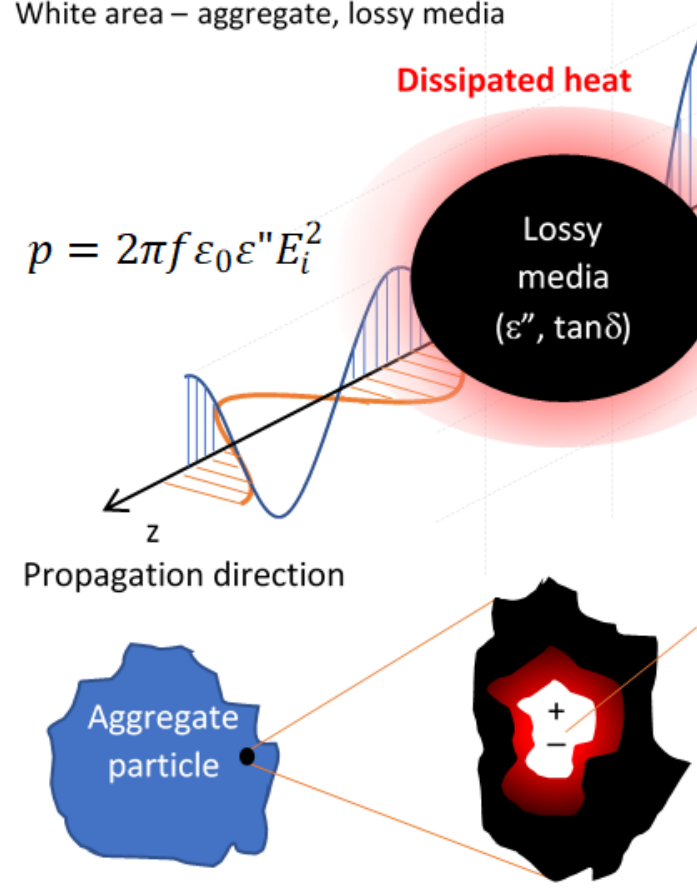

(b)

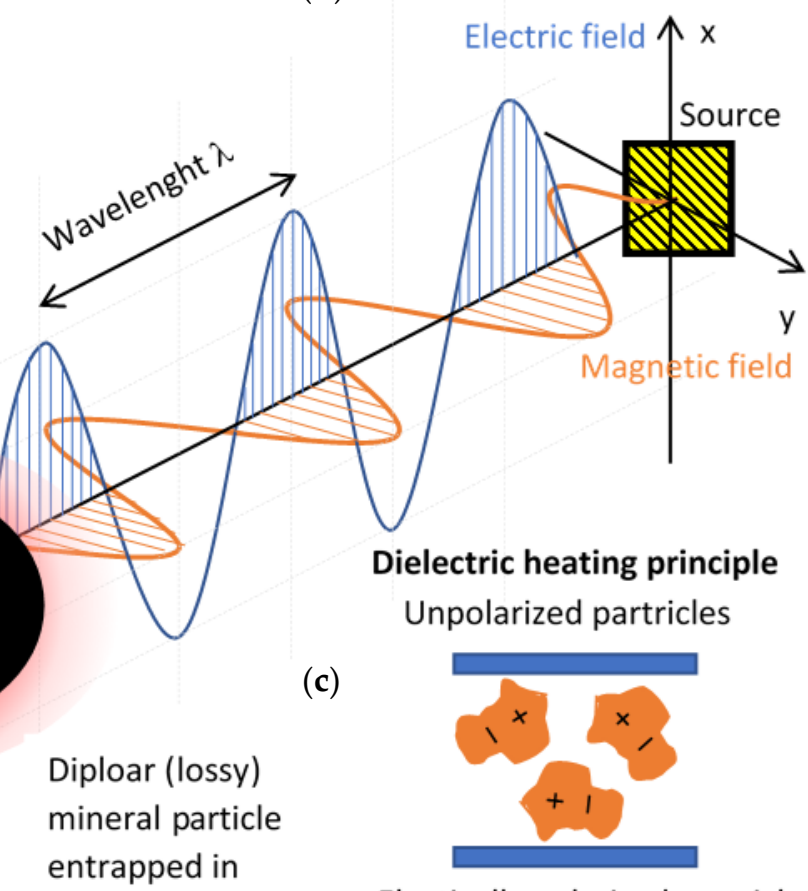

Electically polarized partricles

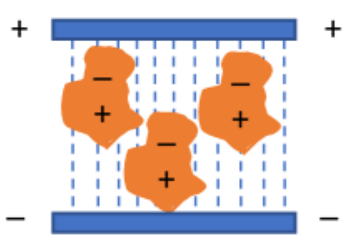

Figure 1. (a) HMA cross-section-white regions are capable of being dielectrically heated; (b) Microwave heating scheme ( $\mathrm{p}$-power density in Watts $/ \mathrm{m}^{3}, \varepsilon_{0}$ - electric permittivity of the free-space, $\varepsilon^{\prime \prime}$-dielectric loss constant, $\mathrm{E}_{\mathrm{i}}{ }^{2}-\mathrm{mean}$ square electric field intensity); (c) dielectric heating principle.

\section{Materials and Methods}

\subsection{Testing Program}

The presented research is a part of the research program that consisted of three phases:

- $\quad$ Phase 1-the laboratory evaluation of dielectric properties of asphalt materials and constituting materials (presented in [43]),

- Phase 2-the laboratory evaluation of dielectric heating on the properties of asphalt, aggregate and bitumen,

- $\quad$ Phase 3-the real-scale experiment of the use of dielectric heating during construction and repair process of the asphalt pavement.

There were several prototype devices designed within the scope of the research program, different resonators for evaluation of dielectric properties of asphalt and its constituents, microwave applicator for applying the dielectric heating to the test specimens and the prototype microwave applicator for the treatment of asphalt pavement during construction and repair process. This article focuses on the third phase of the research program, the real-scale treatment of longitudinal joints and cracks. For the durability considerations, there were several testing techniques used considering mechanical strength of asphalt mixes sampled from the joint or crack area. Strength parameters were assessed directly on testing specimens in different temperatures that are likely to occur in natural conditions. To assess the influence of microwave heating on the asphalt pavement durability, there 
were also some material (bitumen) aging tests performed. These tests indicate predicted pavement cracking susceptibility performance.

\subsection{Design of Experiment, Scope of Research, Test Section}

There were three main objectives of the testing program presented in this paper:

- to evaluate if microwave-assisted joint construction technique has advantages over traditional methods of joint construction,

- to evaluate the effectiveness of crack repair using microwave heating technique,

- to consider if dielectric heating causes more severe damage to the bituminous binder than traditional heating.

The whole experiment was meant to evaluate the in-situ effectiveness of the microwave applicator designed within the scope of NGAM2 project [44]. This article focuses on the performance evaluation of chosen joint construction techniques commonly used in Poland, together with an innovative technique of microwave joint treatment. The full spectrum of joint techniques used in road practice was chosen. There were three groups of joint construction technologies and one crack repair technique evaluated, and their description and abbreviation used in this article are shown in Table 2. It is worth mentioning that direct comparison is possible between VJ, IR (formally VJ + IR) and MW (formally VJ + MW) because all these types of joints are formed in the vertical plane. Sealed type joints, namely $\mathrm{T} 1, \mathrm{~T} 2, \mathrm{P} 1$ and P2 (formally VJ $+\mathrm{T} 1, \mathrm{VJ}+\mathrm{T} 2, \mathrm{VJ}+\mathrm{P} 1$ and $\mathrm{VJ}+\mathrm{P} 2$ ) were of similar geometry but additional material was added, which affects the joint properties. The performance of joint construction techniques and crack repair was limited to direct mechanical tests on specimens cored from joints, density measurements, as well as tests of bitumen prepared in laboratory conditions.

Table 2. Evaluated joint construction technologies and crack repair.

\begin{tabular}{|c|c|c|c|c|}
\hline Group & Description & Sub-Group & Abbr. & Illustration \\
\hline \multirow{2}{*}{ Untreated } & \multirow{2}{*}{$\begin{array}{l}\text { This technology is } \\
\text { commonly practiced } \\
\text { when the treated group } \\
\text { is not used; it can be } \\
\text { considered as a } \\
\text { reference technology in } \\
\text { this experiment. It } \\
\text { comprises two } \\
\text { subgroups. }\end{array}$} & $\begin{array}{l}\text { skewed joint (formed with the use of plate } \\
\text { attached to roller compactor); slope of } 60^{\circ} \\
\text { in asphalt layer is formed; next hot-paved } \\
\text { layer can be placed by cold lane with a } \\
\text { negative slope }\end{array}$ & SJ & \\
\hline & & $\begin{array}{l}\text { vertical joint (cut-off-on the fresh mix, } \\
\text { with a knife attached to roller compactor); } \\
\text { the vertical edge is formed; next } \\
\text { hot-paved layer can be placed by cold } \\
\text { lane with a vertical edge }\end{array}$ & VJ & \\
\hline \multirow{2}{*}{ Treated } & \multirow{2}{*}{$\begin{array}{l}\text { This technology is } \\
\text { neither commonly } \\
\text { known nor frequently } \\
\text { used; it can be treated } \\
\text { as an experimental and } \\
\text { innovative group }\end{array}$} & $\begin{array}{l}\text { vertical joint (as above) followed by } \\
\text { infrared gas burner used for heating of } \\
\text { joint; Infrared (IR) heating can be applied } \\
\text { before, during or after next hot-paved } \\
\text { layer is placed }\end{array}$ & IR & \\
\hline & & $\begin{array}{l}\text { vertical joint (as described in VJ subgroup) } \\
\text { followed by microwave applicator used } \\
\text { for heating of joint; Microwave (MW) } \\
\text { heating can be applied before, during or } \\
\text { after next hot-paved layer is placed }\end{array}$ & MW & \\
\hline
\end{tabular}


Table 2. Cont.

\begin{tabular}{|c|c|c|c|c|}
\hline Group & Description & Sub-Group & Abbr. & Illustration \\
\hline \multirow{2}{*}{ Sealed } & \multirow{2}{*}{$\begin{array}{l}\text { This technology is most } \\
\text { commonly used; there } \\
\text { are additional } \\
\text { thermoplastic, } \\
\text { bitumen-based } \\
\text { materials applied to } \\
\text { seal the vertically } \\
\text { performed joint }\end{array}$} & $\begin{array}{c}\text { vertical joint (as described in VJ subgroup) } \\
\text { followed by application of thermoplastic } \\
\text { bituminous sealing tapes before placing of } \\
\text { next hot-paved layer }\end{array}$ & $\begin{array}{l}\mathrm{T} 1 \\
\mathrm{~T} 2\end{array}$ & \\
\hline & & $\begin{array}{l}\text { vertical joint (as described in VJ subgroup) } \\
\text { followed by application of bituminous } \\
\text { sealing paste: } \\
\text { organic solvent-based } \\
\text { bitumen emulsion based before placing of } \\
\text { next hot-paved layer }\end{array}$ & $\begin{array}{l}\text { P1 } \\
\text { P2 }\end{array}$ & \\
\hline Crack repair & $\begin{array}{l}\text { Crack was repaired } \\
\text { using microwave } \\
\text { heating technique }\end{array}$ & $\begin{array}{l}\text { microwave applicator is used to reheat the } \\
\text { cracked pavement; additional operations } \\
\text { can be added before (e.g. cleaning) or } \\
\text { after (remixing, compaction) the } \\
\text { microwave treatment }\end{array}$ & $\mathrm{CR}$ & \\
\hline
\end{tabular}

To summarize, the independent variables were the joint-forming techniques and bitumen aging techniques, while the dependent variables were the strength and density characteristics of joints and bitumen parameters calculated on basis of dynamic shear rheometer analysis.

The whole experiment was performed in operational conditions, on a real-scale road test section, constructed under controlled conditions, using an ordinary roadworks equipment. The test section was a 2-lane, $95 \mathrm{~m}$ long full-scale asphalt pavement, comprising crushed stone sub-base $(20 \mathrm{~cm}$ thick), two AC $0 / 16 \mathrm{~mm}$ layers (each $10 \mathrm{~cm}$ thick) and SMA $0 / 8 \mathrm{~mm}$ layer ( $5 \mathrm{~cm}$ thick). AC 16 asphalt mix was used to pave the base course and binder course, while SMA 8 mix was used to pave wearing course. The test section was divided into subsections, which were doubled for each joint construction technique. Figure 2 presents the schema of the test section.

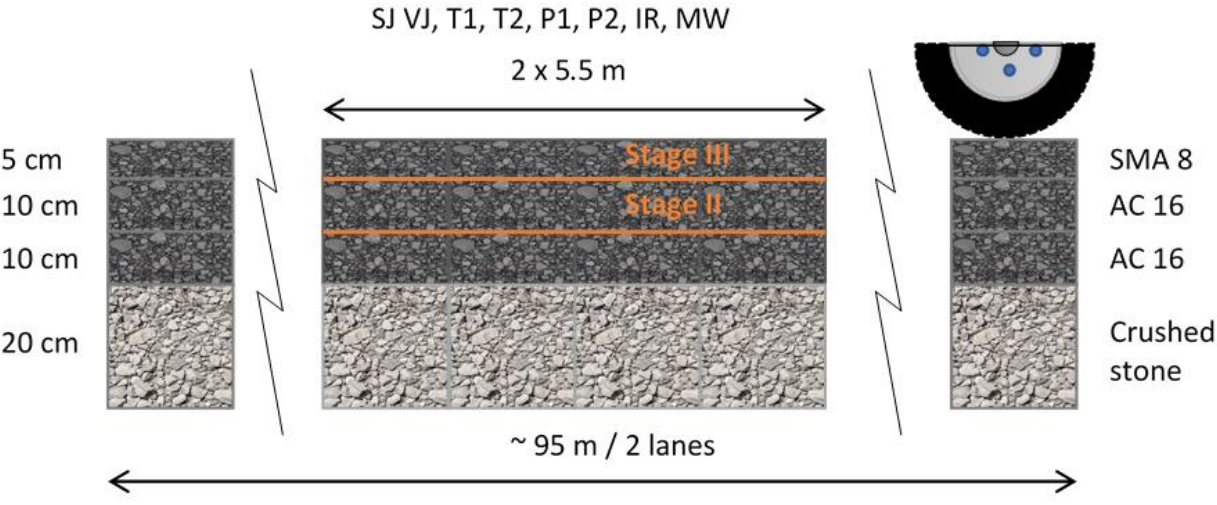

Figure 2. The schematic longitudinal cross-section of the longitudinal joints construction test section.

\subsection{Materials}

Test section was made of asphalt layers. Basic physical, functional and dielectric properties of constituent materials used in asphalt mix design are presented in Tables A1-A3 (Appendix A). Properties and respective standards were also presented.

Mix designs used to form asphalt layers are presented in Table 3. Pavement lanes were intentionally paved in two separate processes. Hot lane was paved next to the lane that 
has already cooled down. There was different technology for constructing longitudinal joints used. Longitudinal joints were formed between binder courses (designation-II) and between wearing courses (designation-III). Both, the constituent materials as well as the layer configurations were described in Table 4.

Table 3. Asphalt mix design used in the project.

\begin{tabular}{|c|c|c|c|c|}
\hline Mix Designation & SMA 8 G & SMA 8 B & AC $16 \mathrm{~W}$ & AC 16 B \\
\hline Aggregate Type & $100 \%$ Gabbro & $100 \%$ Basalt & $100 \%$ Limestone & $100 \%$ Basalt \\
\hline Sieve Size, mm (Square Opening) & $\%$ Mass & $\%$ Mass & $\%$ Mass & $\%$ Mass \\
\hline 22.4 & - & - & 100.0 & 100.0 \\
\hline 16 & - & - & 97.9 & 98.4 \\
\hline 11.2 & 100.0 & 100.0 & 77.3 & 76.3 \\
\hline 8 & 96.6 & 96.8 & 60.8 & 59.4 \\
\hline 5.6 & 59.7 & 55.0 & 46.9 & 46.2 \\
\hline 2 & 29.5 & 27.7 & 24.9 & 27.7 \\
\hline 0.5 & - & - & 13.3 & 13.3 \\
\hline 0.125 & 12.3 & 12.5 & 7.5 & 8.1 \\
\hline 0.063 & 11.0 & 10.0 & 6.5 & 6.6 \\
\hline Binder & 7.3 & 6.7 & 4.3 & 4.6 \\
\hline Binder type & PMB 45/80-55 & PMB 45/80-55 & $35 / 50$ & $35 / 50$ \\
\hline Max density, $\mathrm{Mg} / \mathrm{m}^{3}$ & 2.601 & 2.566 & 2.528 & 2.692 \\
\hline Bulk density ssd, $\mathrm{Mg} / \mathrm{m}^{3}$ & 2.530 & 2.479 & 2.414 & 2.525 \\
\hline Voids content, $\% v / v$ & 2.7 & 3.4 & 4.4 & 6.2 \\
\hline Dielectric constant $\varepsilon^{\prime}$ & $5.76-6.04$ & $6.45-6.74$ & $6.51-7.01$ & $6.60-7.22$ \\
\hline
\end{tabular}

Table 4. Stages of experiment.

\begin{tabular}{ccc}
\hline Stage of the Experiment & Location of Joint & Jointed Mixes Types \\
\hline II & the joint between binder courses & AC 16 W-AC 16 B \\
III & hot by cold & AC 16 W-AC 16 W \\
IV & the joint between wearing courses & SMA 8 G-SMA 8 B \\
SMA 8 B-SMA 8 B \\
AC 11-AC 11
\end{tabular}

There were four types of sealing materials used in this experiment. These were two sealing tapes (T1 and T2) and two sealing pastes (designated as P1 and P2). Properties of these materials are presented in Table 5 .

Table 5. Characteristics of sealing materials.

\begin{tabular}{|c|c|c|c|c|}
\hline Material Designation & T1 & T2 & P1 & $\mathbf{P 2}$ \\
\hline Material Type & $\begin{array}{l}\text { Bituminous } \\
\text { Sealing Tape }\end{array}$ & $\begin{array}{l}\text { Bituminous Sealing Tape } \\
\text { (Self-Adhesive) }\end{array}$ & $\begin{array}{l}\text { Bituminous Sealing } \\
\text { Paste (Solvent-Based) }\end{array}$ & $\begin{array}{l}\text { Bituminous Sealing Paste } \\
\text { (Emulsion-Based) }\end{array}$ \\
\hline Cone penetration, $0.1 \mathrm{~mm}$ & 49.6 & 43.0 & 32.3 & 40.0 \\
\hline Softening point, ${ }^{\circ} \mathrm{C}$ & $>150$ & 113.9 & $>150$ & $>150$ \\
\hline Flow resistance, $\mathrm{mm}$ & 0.0 & 0.0 & 0.0 & 0.0 \\
\hline Elastic recovery, \% & 11 & 20 & 14 & 10 \\
\hline $\begin{array}{l}\text { Frost resistance, balls uncracked } \\
\text { Continuous extension }\end{array}$ & 4 & 4 & 4 & 4 \\
\hline -max. elongation, \% & $\geq 10$ & $\geq 10$ & $\geq 10$ & 3 \\
\hline -max. force, $\mathrm{kN}$ & $\overline{5} .43$ & $\overline{13} .74$ & $\overline{4} .10$ & 8.27 \\
\hline Type of break at $10 \%$ & No break & No break & No break & Cohesion break \\
\hline Cold bending (temp.) & $\begin{array}{l}\text { No cracks } \\
-20{ }^{\circ} \mathrm{C}\end{array}$ & $\begin{array}{l}\text { No cracks } \\
-10{ }^{\circ} \mathrm{C}\end{array}$ & - & - \\
\hline \multicolumn{5}{|l|}{ Discontinuous extension at $-10{ }^{\circ} \mathrm{C}$} \\
\hline$-\%$ & 33 & 33 & 33 & 33 \\
\hline -max. tension stress, $\mathrm{MPa}$ & 0.2 & 0.6 & 1.5 & 1.0 \\
\hline
\end{tabular}




\subsection{Test Specimens and Test Methods}

Asphalt mixture specimens were cored form the real-scale asphalt pavement using a diamond coring machine (100 $\mathrm{mm}$ and $150 \mathrm{~mm}$ diameter cylindrical specimens) or cut from pavement using a saw $(100 \mathrm{~mm} \times 100 \mathrm{~mm} \times 200 \mathrm{~mm}$ perpendicular specimens $)$. On every type of longitudinal joint section there were at least five specimens taken. Specimens were extracted from the pavement in two stages, stage II and stage III separately (see Table 4). After the extraction process, the longitudinal joint (or healed crack) was located in the middle of the specimen, shown in Figure 3. In the laboratory, specimens were cleaned and cut on the precision saw to level the specimens' surfaces. Perpendicular specimens and $150 \mathrm{~mm}$ cylindrical specimens were additionally cut in half to gain proper specimen size described in Table 6 . The conditioning process was adequate to the testing protocol described in Table 6.

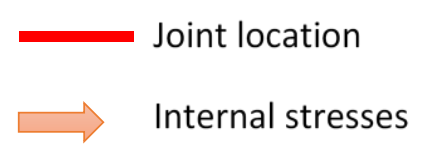

(a)
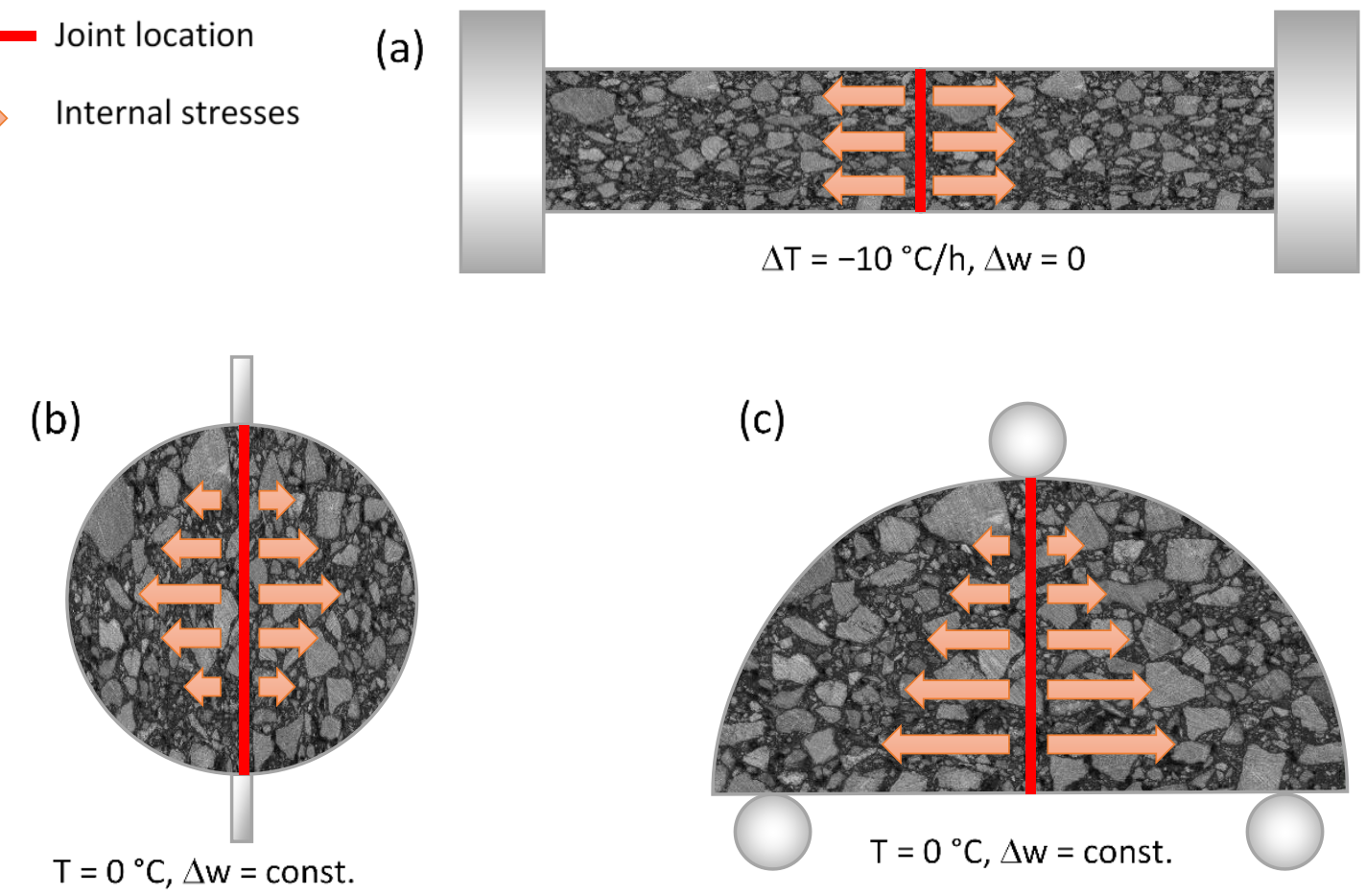

Figure 3. (a) Joint location in TSRST specimen (deflection rate $-\Delta \mathrm{w}=0 \mathrm{~mm} / \mathrm{min}$ ); (b) Joint location in ITS specimen (deflection rate $-\Delta \mathrm{w}=50 \pm 2 \mathrm{~mm} / \mathrm{min}$ ); (c) Joint location in SCB specimen (deflection rate $-\Delta \mathrm{w}=5 \pm 0.2 \mathrm{~mm} / \mathrm{min}$ ).

Table 6. Description of testing methodology and specimens.

\begin{tabular}{|c|c|c|c|}
\hline Test Method & Test Protocol & Specimen Size, Type & Test Conditions \\
\hline \multicolumn{4}{|c|}{ Mechanical Tests } \\
\hline $\begin{array}{l}\text { Indirect tensile strength ITS } \\
\quad \text { (split tension test) }\end{array}$ & PN-EN 12697-23, met. A & $\begin{array}{l}100 \mathrm{~mm} \text { cylindrical, cored from } \\
\text { the pavement }\end{array}$ & $0^{\circ} \mathrm{C}$ \\
\hline $\begin{array}{l}\text { Bending tensile strength SCB } \\
\text { (semi-circular bending) }\end{array}$ & PN-EN 12697-44, no cut & $\begin{array}{l}150 \mathrm{~mm} \text { half-cylindrical, cored } \\
\text { from the pavement and cut in half }\end{array}$ & $0^{\circ} \mathrm{C}$ \\
\hline $\begin{array}{l}\text { Direct tension TSRST (thermal } \\
\text { stress restrained specimen) }\end{array}$ & PN-EN 12697-46, TSRST & $\begin{array}{l}40 \mathrm{~mm} \times 40 \mathrm{~mm} \times 200 \mathrm{~mm} \text { beam, } \\
\text { cut from } 100 \mathrm{~mm} \times 100 \mathrm{~mm} \times \\
200 \mathrm{~mm} \text { slab cut from pavement }\end{array}$ & $\begin{array}{l}(+10)-(-40){ }^{\circ} \mathrm{C} \\
\left(\Delta=-10^{\circ} \mathrm{C} / \mathrm{h}\right)\end{array}$ \\
\hline \multicolumn{4}{|c|}{ Physical Properties } \\
\hline Degree of compaction & $\begin{array}{c}\text { PN-EN 13108-21, C.4 } \\
\text { PN-EN } 12697-6, \text { met. B, } 25^{\circ} \mathrm{C} \text { and D }\end{array}$ & $100 \mathrm{~mm}$ cylindrical cores & $+25^{\circ} \mathrm{C}$ \\
\hline
\end{tabular}


Bitumen samples were supplied by bitumen refinery and prepared in the laboratory and subjected to both standard aging protocol [45] (Rotating Thin Film Oven Test-RTFOT + Pressure Aged Vessel-PAV) and the microwave conditioning process described later.

It is worth mentioning that some problems were occurring during the operations on specimens. Not all specimens that were meant to be further evaluated and tested went positively through the whole process of cutting, reducing and conditioning. Specimens sealed with P1 solvent-based paste after sampling the joint appeared to be very soft (gently movable) and the soft scent of solvent was present. It means that not the whole solvent evaporated after the installation process. This "softness" of the specimen resulted in an overall lowering of the stiffness modulus and strength in different test temperatures.

To evaluate the performance of joints, there were two main measuring techniques used. The first technique used was the mechanical tension performance measurements, which were meant to confirm the influence of different joint construction techniques on adhesion and cohesion, generally the bonding quality of the joint. The second technique was the compaction degree measurement, which was meant to evaluate the most important factor, the quality of roadworks. Mechanical performance was evaluated in terms of tensile strength in different testing modes and temperatures. There were three testing techniques used: indirect tension (IT-CY [46]), semi-circular bending (SCB [47]) and thermal stress restrained tension test (TSRST [48]), so mechanical tests were based on standard test protocols. Compaction degree was calculated based on the bulk density test method saturated surface dry (ssd) and reference Marshall bulk density (ssd). Detailed conditions of the tests and specimen sizes are presented in Table 6.

Direct tension in the thermal cracking test was calculated using Equation (1) (Figure 3a).

$$
\sigma_{\max }=\frac{F_{\max }}{b \cdot t}
$$

where $\sigma_{\max }$-tensile strength in megapascals, $F_{\max }$ —ultimate force in Newtons, $b$-specimen width in millimeters, $t$ - thickness of the specimen in millimeters.

Indirect tensile strength was calculated using the Equation (2) (Figure 3b).

$$
\text { ITS }=\frac{2 \cdot P}{\pi \cdot D \cdot H}
$$

where ITS —indirect tensile strength expressed in megapascals, $P$ - ultimate force, expressed in Newtons, $D$-diameter of the cylindrical specimen expressed in millimeters, $H$-the height of the specimen expressed in millimeters.

Bending tensile strength SCB was calculated using the Equation (3) (Figure 3c).

$$
\sigma_{\max }=\frac{4.263 \cdot F_{\max }}{D \cdot t}
$$

where $\sigma_{\max }$-tensile strength in megapascals, $F_{\max }$ —ultimate force in Newtons, $D$-specimen diameter in millimeters, $t$-thickness of the specimen in millimeters.

Compaction degree was calculated according to Equation (4).

$$
P=\frac{B_{\text {specimen }}}{B_{\text {reference }}}
$$

The schema of the joint locations within the test specimens is shown in Figure 3.

The durability of asphalt pavements can be expressed using different characteristics, but there are two dominating factors: rutting and cracking. In addition to the above mentioned mechanical tests describing the susceptibility to cracking, there was also a wider analysis performed on bitumen properties. There are two parameters [49] based on bitumen properties, which were found to correlate with field observed cracking of asphalt pavements [50]. The first value is the G-R parameter, which describes the position of the bitumen master curve, which is tested at $15{ }^{\circ} \mathrm{C}$ and the shearing speed of $0.005 \mathrm{rad} / \mathrm{s}$. 
The parameter's values classified below $180 \mathrm{kPa}$ are found to be of low risk of asphalt pavement cracking, while values over $450 \mathrm{kPa}$ are pointing the high risk of the pavement cracking. The second parameter is the R-value, which describes the master curve shape. It is calculated based on the bitumen DSR test results, where the intersection point of glassy modulus line Gg (assumed 2.5 GPa) and asymptotic line to the initial phase of complex modulus vs. phase angle plot is determined. Rheological index R-value is the difference between glassy modulus $\mathrm{Gg}$ and complex modulus in the transition frequency. Bitumen $\mathrm{R}$-value exceeding 3 is estimating the high potential risk of the pavement cracking.

In this analysis, there were 2 bitumen types tested, the 35/50 and PMB 45/80-55. The processing cycle consisted of RTFOT (referred to as 1R), PAV (referred to as $1 \mathrm{P}$ ) and microwave conditioning process (M:800-900). RTFOT is a well-known standard processes for short-term aging of bitumen (simulates manufacturing and hot-mix placement aging). The testing specimens of $35 \mathrm{~g}$ are poured in to the glass cylinders and placed in special rolling rack in the temperature controlled chamber at $163{ }^{\circ} \mathrm{C}$ for $85 \mathrm{~min}$, with airflow into glass bottles of $4000 \mathrm{~mL} / \mathrm{min}$ ). PAV aging is known as long-term bitumen aging (simulates 7 to 10 years of in-service conditions). The bitumen samples are kept on stainless steel pans in temperature of $100{ }^{\circ} \mathrm{C}$, pressure of $2.1 \mathrm{MPa}$ for $20 \mathrm{~h}$.

As regards the microwave heating, authors of the publication [45] proved that $11 \mathrm{~g}$ bitumen specimen subjected for $7 \mathrm{~h} 20 \mathrm{~min}$ of microwave heating combining the temperature of $143{ }^{\circ} \mathrm{C}$, different fan speed, $3.08 \mathrm{MPa}$ air pressure and 930-1035 W microwave heating resulted in bitumen oxidation comparable to RTFOT + PAV aging protocol. In our research, dielectric heating was applied to the $500 \mathrm{~g}$ neat bitumen sample poured into $1000 \mathrm{~mL}$ quartz glass beaker (0A + M sample). So the prepared specimen was put into a microwave chamber and heated at $800 \mathrm{~W} @ 2.450 \mathrm{GHz}$ for $900 \mathrm{~s}(15 \mathrm{~min})$. The microwave heating conditions were chosen from practical reasons as an ultimate time conditions in this study. $1 \mathrm{R}+\mathrm{M}$ specimens were subjected to microwave heating after pouring bitumen from RTFOT glass cylinders to one quartz glass beaker (ca. $500 \mathrm{~g}$ ). 1P + M specimens were subjected to microwave heating after pouring bitumen from PAV stainless steel pans to one quartz glass beaker (ca. $500 \mathrm{~g}$ ) in the original PAV dishes. The testing plan is presented in Table 7.

Table 7. Aging plan for tested bitumen samples.

\begin{tabular}{cccc}
\hline Aging Stages & Description & $35 / 50$ & PMB 45/80-55 \\
\hline No aging & 0A & + & + \\
No aging + microwaves & OA + M:800-900 & + & + \\
RTFOT & $1 \mathrm{R}$ & + & + \\
RTFOT + PAV & $1 \mathrm{P}$ & + & + \\
RTFOT + microwaves & $1 \mathrm{R}+\mathrm{M}: 800-900$ & + & + \\
RTFOT + PAV + microwaves & $1 \mathrm{P}+\mathrm{M}: 800-900$ & + \\
\hline
\end{tabular}

\subsection{Microwave Applicator}

A microwave applicator was designed and constructed in the scope of NGAM2 project [44]. The technical details were presented in the recent publication [43]. In this study, the unique real-scale microwave applicator was designed and installed on a trailer, which was towed by a car. The $\mathrm{m}-\mathrm{w}$ applicator was supplied with the electricity from the portable power generator. Construction details, as well as technology steps, weren't publicized, as they are protected know-how for the scientific-industry consortium. Generally, the designed applicator had a total microwave nominal power of $7 \mathrm{~kW}$ at $2.450 \mathrm{GHz}$. The design of the applicator consisted of sets of waveguides and microwave generators, whose geometry was adjusted to the linear heating capability, considering linear joint-forming technique and crack healing. 


\subsection{Microwave Assisted Processes}

The joint-forming microwave-assisted process goal was to achieve pavement temperature on both sides of the joint of ca. $140{ }^{\circ} \mathrm{C}$, what enabled the extra compaction process. After pavement joint heat-up on both lanes (cold and hot lane), it was possible to achieve extra compaction process. The heat-up process, which had an initial temperature of ca. $80{ }^{\circ} \mathrm{C}$ (hot lane) and ca. $40{ }^{\circ} \mathrm{C}$ (cold lane) took from $1 \mathrm{~min} / 1 \mathrm{~m}$ (basalt aggregate) to $10 \mathrm{~min} / 1 \mathrm{~m}$ (limestone aggregate). There was a known phenomenon occurring during the application of microwave, the rise of asphalt pavement due to the sudden rise of steam pressure. This phenomenon had been observed since the beginning of asphalt treatment using microwave energy. In general, it helps to achieve the assumed goal, the additional compaction of pavement. After the pavement has risen it was rolled using steel-roller compactor and the pavement surface was levelled before cooling down. Both, the effect of joint heating and the effect of blistering, are presented in Figure 4.

(a)

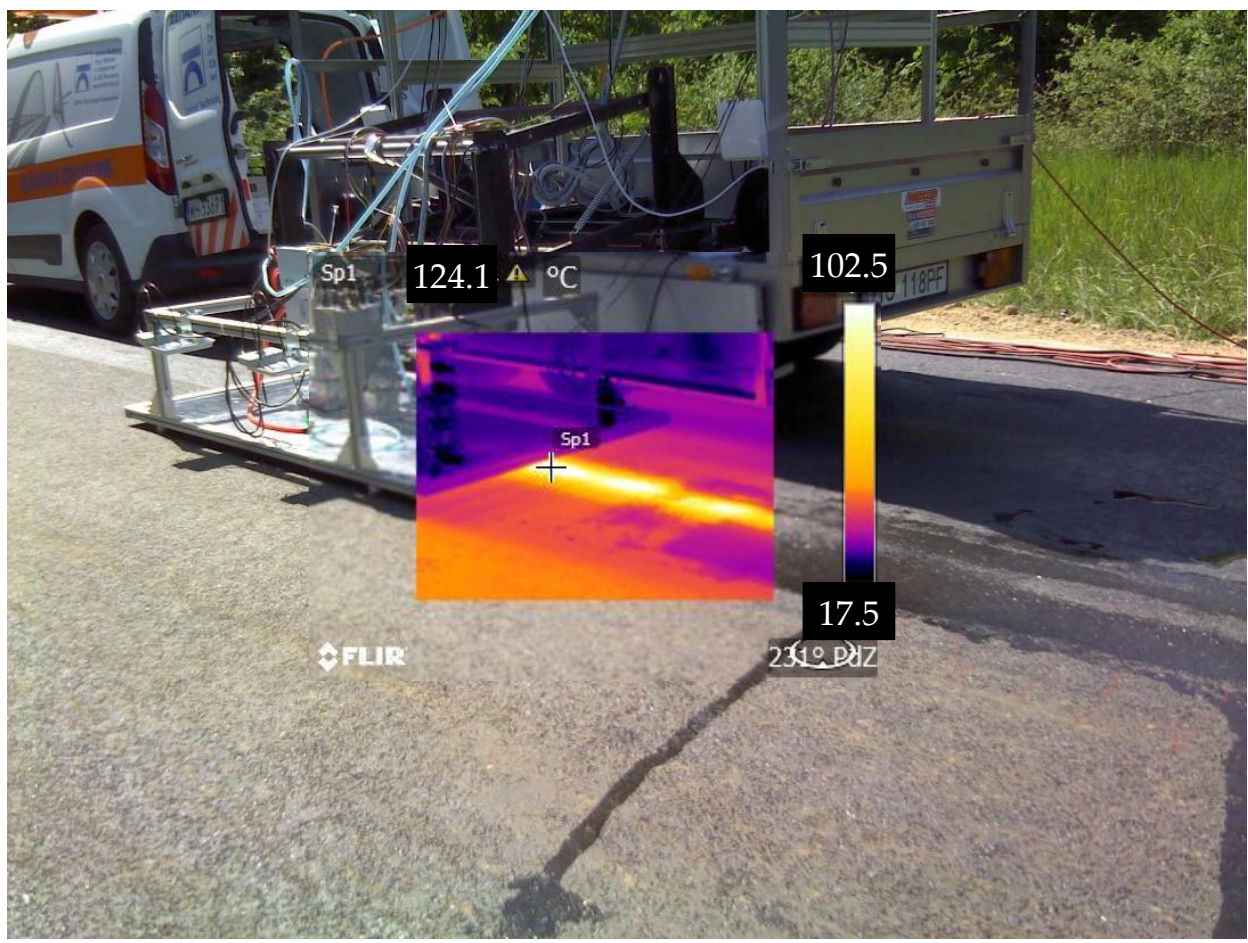

(b)

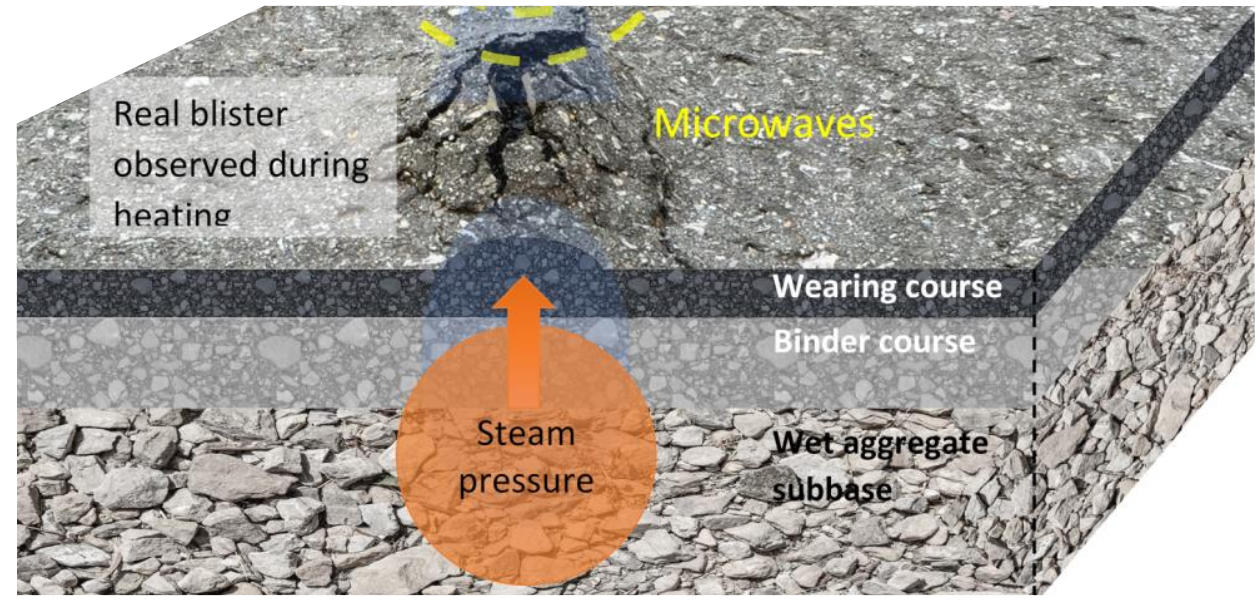

Figure 4. (a) Thermal effect of pavement heating using microwave applicator; (b) Blistering phenomenon during heating of asphalt. 
In addition to the longitudinal joints evaluation experiment, there was also a trial of cracked pavement repair using microwave applicator performed. The experiment was done on cracked, two-layered asphalt pavement, made of the asphalt concrete (AC 11 $\mathrm{B}$ and $\mathrm{AC} 16 \mathrm{~B}), 5+5 \mathrm{~cm}$ thick, with limestone aggregates, paved over the limestone crushed aggregate unbound base. The pavement was built on the crushed stone aggregate base course. The crack in the asphalt layers was a full-depth type $(10 \mathrm{~cm}$ thick), possibly induced by thermal shrinkage of the pavement. Before microwave treatment, the crack was vacuum cleaned and blown with 10 bar air pressure lance. After the preparation process, the microwave applicator was engaged and heated the pavement in the close vicinity of the crack. The heating process ended up with the pavement surface temperature of ca. $140{ }^{\circ} \mathrm{C}$. The evaluated average process speed was ca. $10 \mathrm{~min} / 1 \mathrm{~m}$ of the crack. Due to the blistering phenomenon described later, the pavement moved up and had to be roller compacted to bring the initial surface level. While there are options of remixing the heated asphalt layer or homogenization, no additional activity was applied in this process.

\section{Results}

\subsection{General}

The test results were grouped by the test methods. Statistical analysis of the results was based on confidence intervals for the mean at a $90 \%$ confidence level. Final evaluation of differences between test results was based on ANOVA and Tukey's paired comparisons (unless otherwise stated). To save space, each presented statistic shows only the MW joint type compared to other joint types. Experimental errors were published in terms of the confidence intervals $(\mathrm{CI})$ provided in the figure bars with the probability of $90 \%$. All tables include Difference of levels, Difference of means, Standard Error (SE) of difference and 90\% Confidence Intervals (CI). Tables also contain the adequate statistics: T-values and Adjusted $p$-values.

\subsection{Longitudinal Joints}

\subsubsection{Low-Temperature Cracking TSRST}

TSRST test results (Figures 5 and 6) showed on one hand that microwave MW longitudinal joint together with other heated (IR) or untreated (VJ) joints performed very well as regards ultimate stresses, reaching a level of 3-4 MPa, compared to 2-3 MPa or less on sealed type joints. On the other hand, the ultimate temperatures during the test were also at a very good level (ca. $-15^{\circ} \mathrm{C}$ at stage II or $-30{ }^{\circ} \mathrm{C}$ at stage III), but showed worse performance compared to some of the sealed type joints like T1 and T2 or P1 and P2. An interesting behavior of paste was observed that by relatively low maximum strength at the cracking point, they gained very high elongation and cracked in temperatures reaching $-40{ }^{\circ} \mathrm{C}$ or even less. Generally, stage II test results showed worse performance than stage III, but it can be explained by different asphalt mixes used in the binder and wearing course, as well as different thicknesses of the layers. Also in stage III, there was a bigger specimen population, and contractors do pay more attention to wearing courses construction. Tukey's pairwise comparison is presented in Tables 8 and 9.

It can be concluded that the microwave-heated joint characterized itself with good performance in TSRST. It showed no negative influence comparing to other heated or untreated joint types. In stage III, microwave joint type was proven to have very narrow results range, which can be interpreted as increased uniformity of the joint area in comparison with other jointing techniques. Other jointing techniques gained wider ranges of results or worse mean value of cracking temperatures. It can be caused by lower uniformity of the joint-forming process resulting in higher air voids content, worse uniformity and integrity of the joint and the asphalt layer. Vertical joints, VJ, or skewed joints, SJ, are mostly subjected to errors causing nonuniformity, which is partly reduced using extra heating by microwaves or infrared heating. From these two heating methods, microwave heating is advantageous over infrared heating as a result of its volumetric nature. Infrared heating 
penetrates from the surface to the depth of heated media, and it results in inadequate uniformity, as is the case of microwave heating.

In the case of sealed joint types, it can be noticed that better cracking temperatures together with lower ultimate stresses were achieved. It is caused by good properties of sealing materials, but there is a need for the utilization of extra material. Sealing materials are compounded to achieve a very wide spectrum of working conditions, but a non-renewable material and an extra process have to be incorporated into the road construction process.

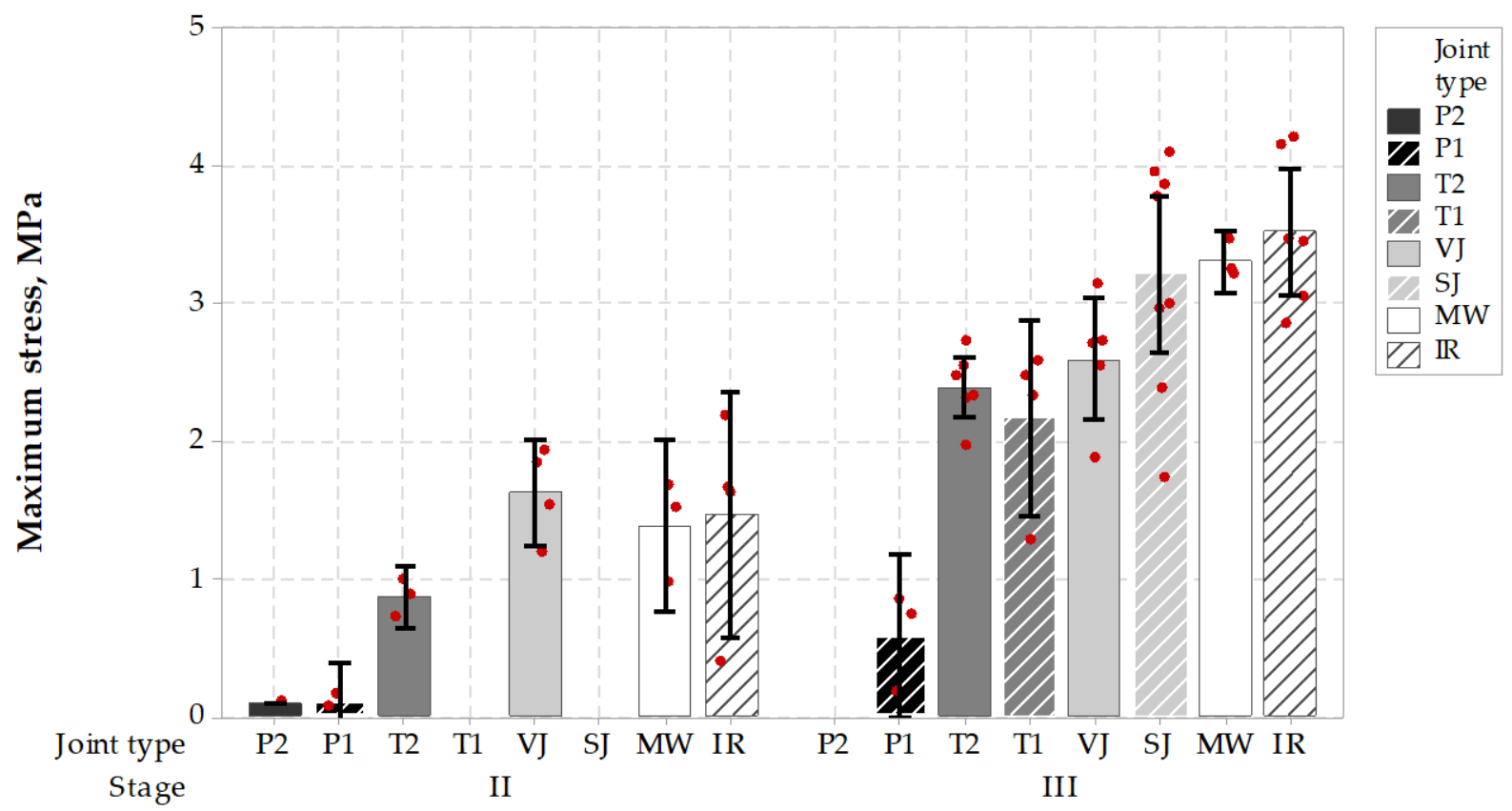

Individual standard deviations are used to calculate the intervals ( $p=90 \%$ ).

Figure 5. Test results of the maximum stress induced in specimens taken from longitudinal joints (the higher, the better).

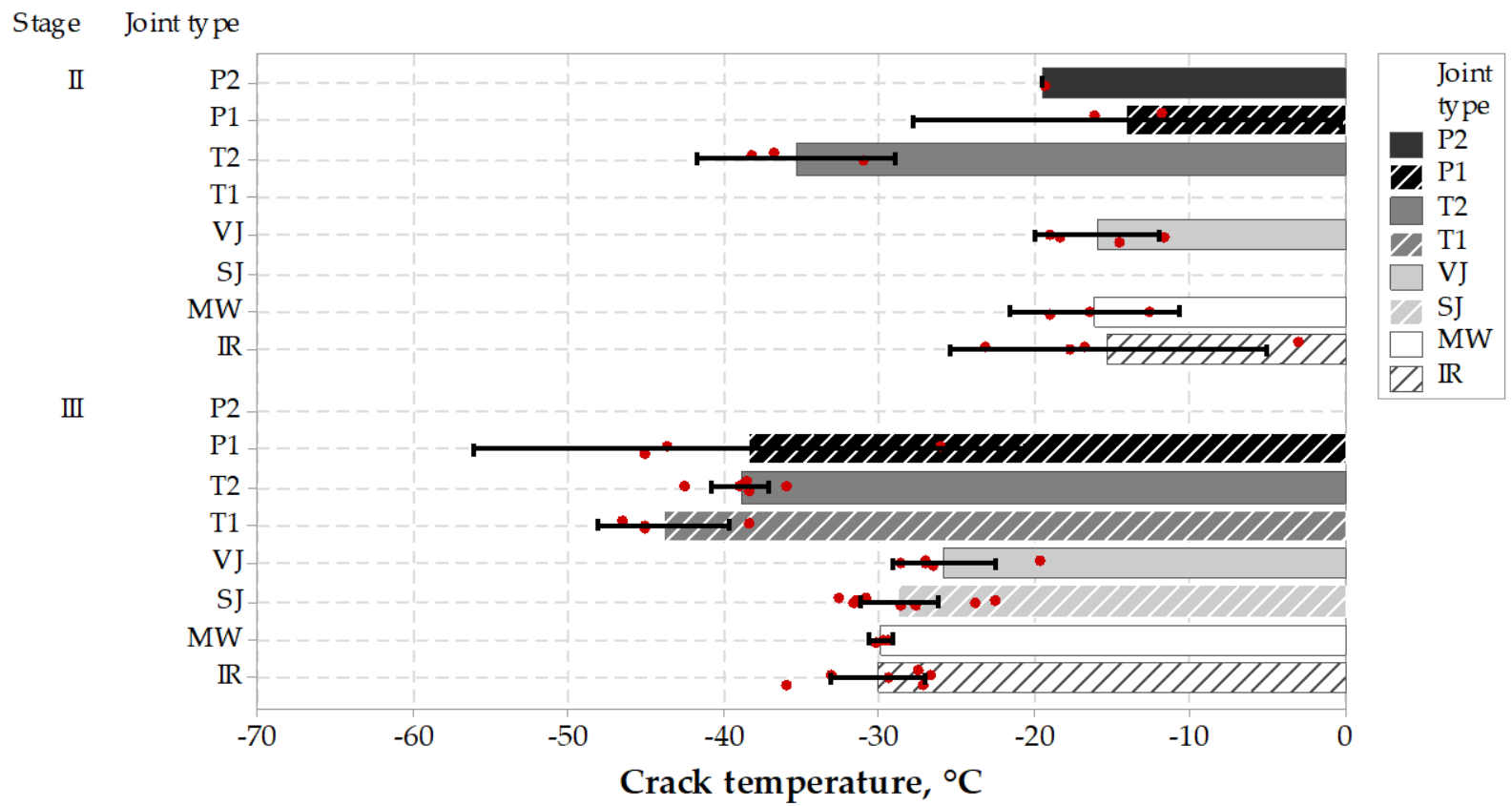

Individual standard deviations are used to calculate the intervals ( $p=90 \%$ ).

Figure 6. Test results of cracking temperature of specimens taken from longitudinal joints (the higher, the better). 
Table 8. Tukey's pairwise comparison for TSRST test-maximum stress.

\begin{tabular}{cccccccc}
\hline Stage & $\begin{array}{c}\text { Difference } \\
\text { of Levels }\end{array}$ & $\begin{array}{c}\text { Difference of } \\
\text { Means, MPa }\end{array}$ & $\begin{array}{c}\text { SE of Difference, } \\
\mathbf{M P a}\end{array}$ & $\mathbf{9 0 \%}$ CI, MPa & $\begin{array}{c}\text { T-Value } \\
\boldsymbol{p} \text {-Value }\end{array}$ \\
\hline II & MW-IR & -0.075 & 0.355 & $(-1.130 ;$ & $0.980)$ & -0.21 & 1.000 \\
II & P1-MW & -1.273 & 0.425 & $(-2.534 ;$ & $-0.012)$ & -3.0 & 0.096 \\
II & P2-MW & -1.281 & 0.537 & $(-2.876 ;$ & $0.314)$ & -2.39 & 0.240 \\
II & T2-MW & -0.52 & 0.380 & $(-1.648 ;$ & $0.608)$ & -1.37 & 0.744 \\
II & VJ-MW & 0.238 & 0.355 & $(-0.817 ;$ & $1.293)$ & 0.67 & 0.982 \\
III & MW-IR & -0.222 & 0.404 & $(-1.374 ;$ & $0.931)$ & -0.55 \\
III & P1-MW & -2.712 & 0.467 & $(-4.042 ;$ & $-1.382)$ & -5.81 \\
III & SJ-MW & -0.083 & 0.387 & $(-1.186 ;$ & $1.020)$ & -0.21 & 0.998 \\
III & T1-MW & -1.138 & 0.437 & $(-2.382 ;$ & $0.107)$ & -2.61 & 1.000 \\
III & T2-MW & -0.91 & 0.404 & $(-2.062 ;$ & $0.242)$ & -2.25 & 0.163 \\
\hline
\end{tabular}

Table 9. Tukey's pairwise comparison for TSRST test-crack temperature.

\begin{tabular}{|c|c|c|c|c|c|c|c|}
\hline Stage & $\begin{array}{l}\text { Difference } \\
\text { of Levels }\end{array}$ & $\begin{array}{l}\text { Difference of } \\
\text { Means, }{ }^{\circ} \mathrm{C}\end{array}$ & $\begin{array}{c}\text { SE of Difference, } \\
{ }^{\circ} \mathrm{C}\end{array}$ & \multicolumn{2}{|c|}{$90 \% \mathrm{CI},{ }^{\circ} \mathrm{C}$} & T-Value & $\begin{array}{c}\text { Adjusted } \\
p \text {-Value }\end{array}$ \\
\hline II & MW-IR & -0.86 & 4.11 & $(-13.08$ & 11.35) & -0.21 & 1.000 \\
\hline II & P1-MW & 2.08 & 4.92 & $(-12.52$ & 16.69) & 0.42 & 0.998 \\
\hline II & P2-MW & -3.34 & 6.22 & $(-21.81$ & 15.13) & -0.54 & 0.993 \\
\hline II & T2-MW & -19.25 & 4.4 & $(-32.31$ & $-6.19)$ & -4.38 & 0.011 \\
\hline II & VJ-MW & 0.17 & 4.11 & $(-12.04$ & 12.39) & 0.04 & 1.000 \\
\hline III & MW-IR & 0.2 & 6.59 & $(-19.09$ & 19.49) & 0.03 & 1.000 \\
\hline III & P1-MW & -8.54 & 7.61 & $(-30.81$ & 13.73) & -1.12 & 0.947 \\
\hline III & P2-MW & 29.83 & 7.61 & $(7.56$ & 52.10) & 3.92 & 0.009 \\
\hline III & SJ-MW & 1.12 & 6.31 & $(-17.35$; & 19.58) & 0.18 & 1.000 \\
\hline III & T1-MW & -14.04 & 7.12 & $(-34.87$ & $6.80)$ & -1.97 & 0.515 \\
\hline
\end{tabular}

Still, the $-30{ }^{\circ} \mathrm{C}$ TSRST cracking temperature in case of a wearing course joint treated by microwaves, or $-15^{\circ} \mathrm{C}$ temperature in case of a binder course treated by microwaves, assures high potential of low-temperature cracking resistance of the formed joint. Low cracking temperature is especially important in the cold climate areas, where joints are especially subjected to cracking and premature deterioration.

\subsubsection{Indirect Tensile Strength ITS}

It was a relatively hard task to core $100 \mathrm{~mm}$ diameter cores directly from longitudinal joints, where the joint should be located directly in the diameter area of the specimen to have successful test results. Thus not all specimens taken from the pavement could be used in ITS test, and they were rejected. Relatively small specimen population was the reason for evaluation of test results from stage II and III joined in one group. Test results (Figures 7 and 8 ) were divided into two main groups, the first with results showing high stresses together with low ultimate strain and the second group with low stresses and high strains. Microwave joint type was placed in the middle of indirect tension results population with ca. 2.7 MPa result, compared to 2.7-4.0 MPa for heated (IR) or untreated joints group (SJ or VJ). Also, the maximum elongation reached by the specimens from treated or untreated joint groups and P2 sealed joints were statistically indifferent from the MW-treated joint technique, while sealed P1, T1 and T2 joint techniques were significantly higher.

Next, the E modulus was calculated as a proportion of maximum ITS stress $(\mathrm{kPa})$ to the ultimate strain value (\%). It represents the stiffness of the joint and can be concluded just as an indicator in the design process of pavement joints (Figure 9). In this comparison, the MW-treated joint reached an average of $446 \mathrm{MPa}$, which places this joint type together with IR and SJ in the group of highest results in this comparison. It is worth mentioning that high stiffness value is believed to influence pavement behavior in low temperatures, while low stiffness properties of the joints with sealing material are meant to dilate and to 
seal the pavement without the possibility of utilizing its properties in pavement response. It may be concluded that MW-treated longitudinal joint test results were positive and placed this jointing technique among other untreated or treated techniques, while sealed joints characterized themselves with lower modulus and higher elongation during testing. Tukey's pairwise comparison is presented in Tables 10 and 11.

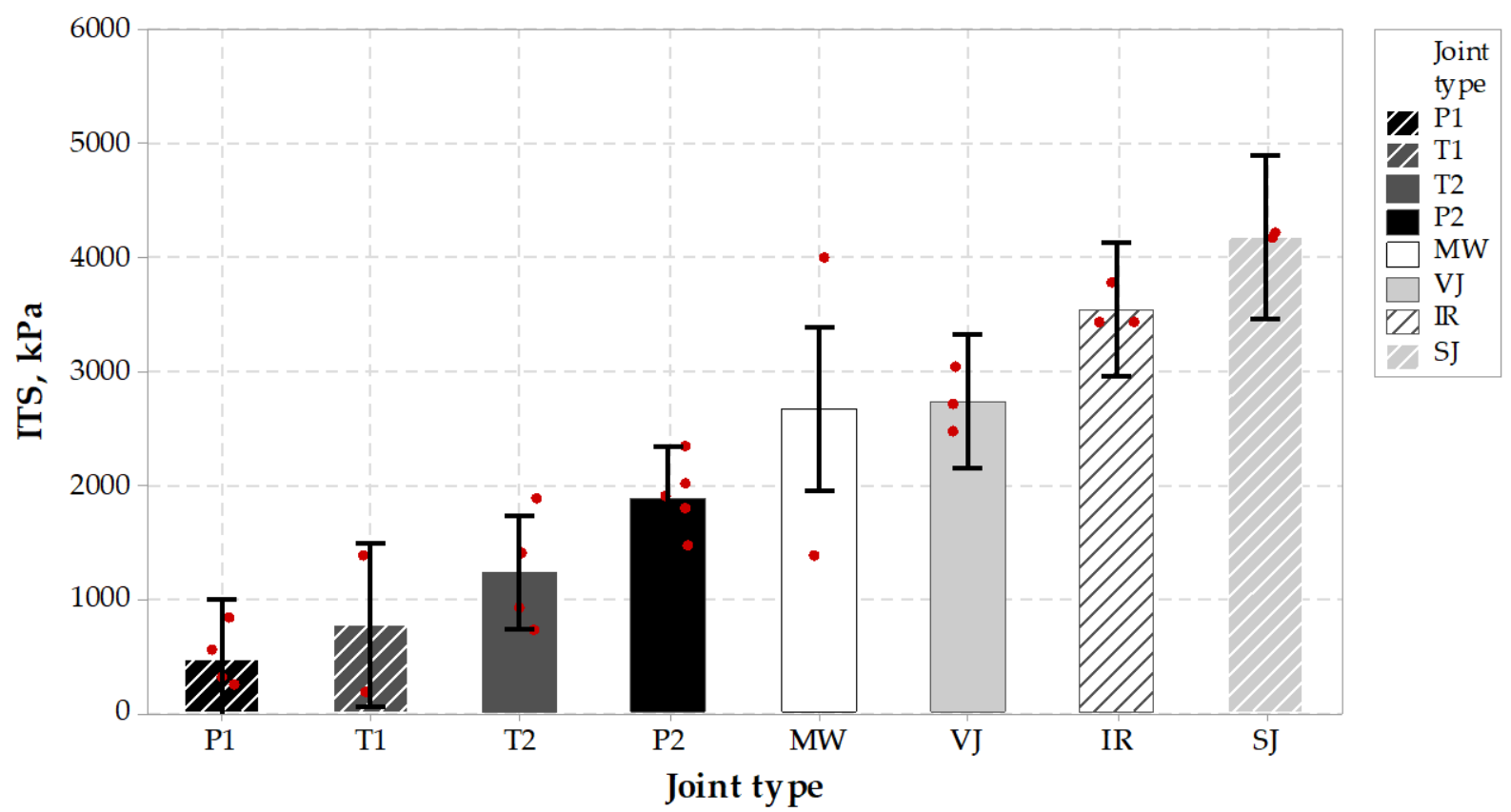

The pooled standard deviation is used to calculate the intervals ( $p=90 \%$ ).

Figure 7. Indirect tension strength test results of specimens taken from longitudinal joints.

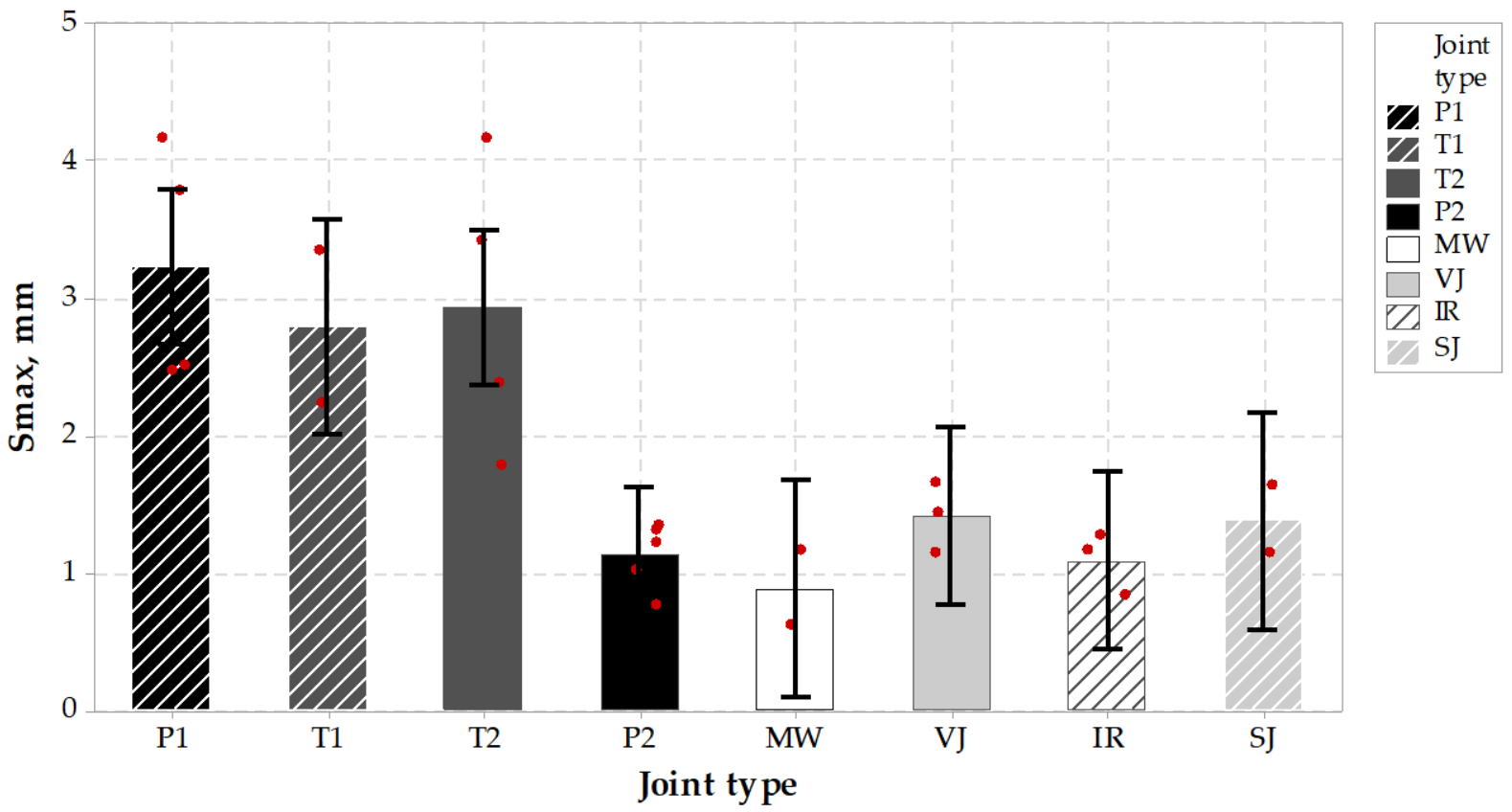

The pooled standard deviation is used to calculate the intervals ( $p=90 \%$ ).

Figure 8. Indirect tension maximum elongation test results of specimens taken from longitudinal joints. 


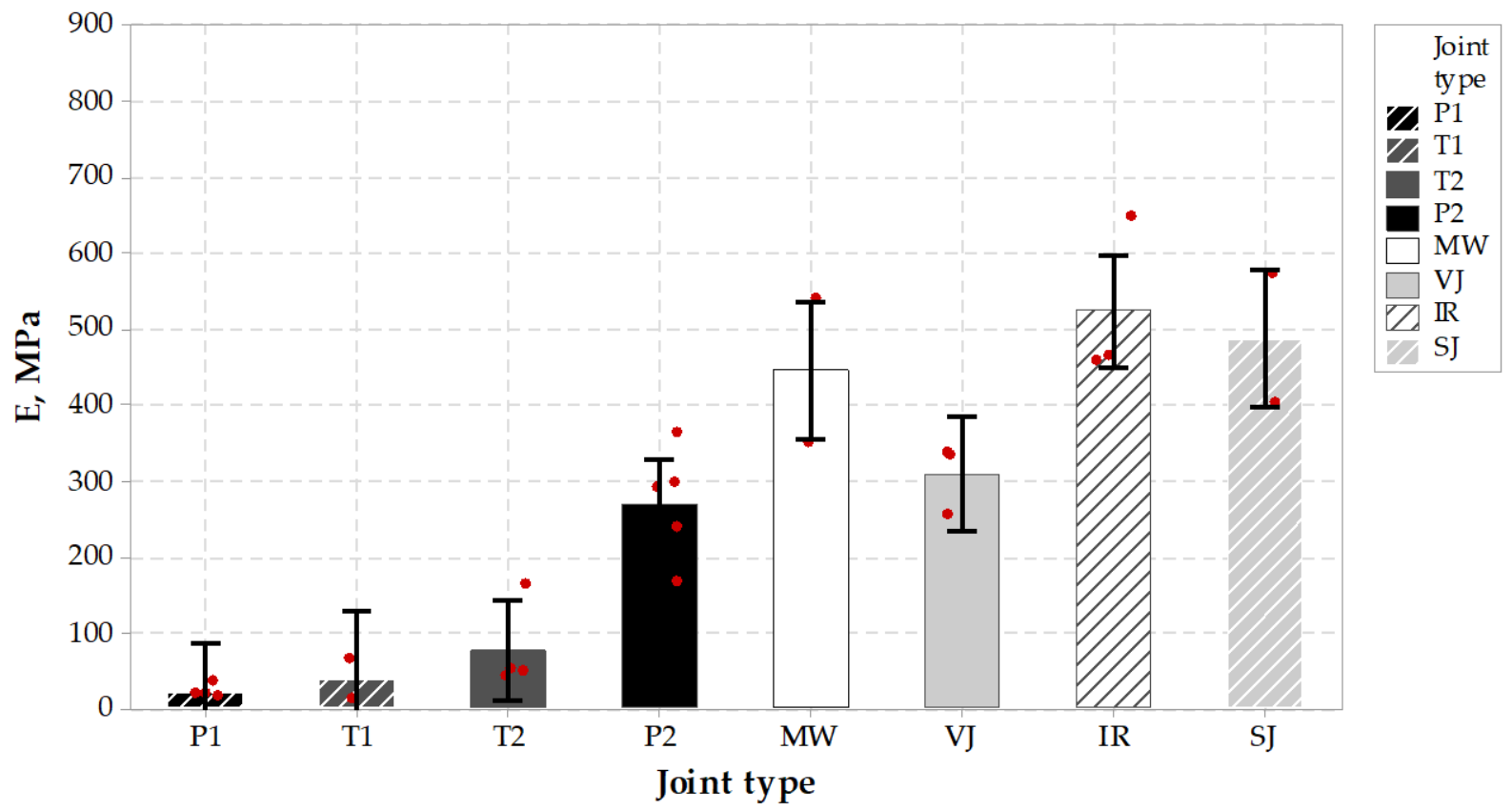

The pooled standard deviation is used to calculate the intervals ( $p=90 \%$ ).

Figure 9. Indirect tension modulus of specimens taken from longitudinal joints.

Table 10. Tukey's pairwise comparison for ITS test strength.

\begin{tabular}{|c|c|c|c|c|c|c|c|}
\hline Stage & $\begin{array}{l}\text { Difference } \\
\text { of Levels }\end{array}$ & $\begin{array}{l}\text { Difference of } \\
\text { Means, MPa }\end{array}$ & $\begin{array}{c}\text { SE of Difference, } \\
\mathrm{MPa}\end{array}$ & \multicolumn{2}{|c|}{$90 \% \mathrm{CI}, \mathrm{MPa}$} & T-Value & $\begin{array}{c}\text { Adjusted } \\
p \text {-Value }\end{array}$ \\
\hline II + III & MW-P1 & 2206 & 498 & (671; & 3742) & 4.43 & 0.008 \\
\hline $\mathrm{II}+\mathrm{III}$ & MW-T1 & 1905 & 575 & $(132 ;$ & 3678) & 3.31 & 0.066 \\
\hline $\mathrm{II}+\mathrm{III}$ & MW-T2 & 1665 & 525 & $(46$ & 3283) & 3.17 & 0.085 \\
\hline $\mathrm{II}+\mathrm{III}$ & MW-P2 & 789 & 481 & $(-694$ & 2273) & 1.64 & 0.722 \\
\hline $\mathrm{II}+\mathrm{III}$ & VJ-MW & 55 & 525 & $(-1564$ & 1674) & 0.10 & 1.000 \\
\hline $\mathrm{II}+\mathrm{III}$ & IR-MW & 860 & 525 & $(-758$ & 2479) & 1.64 & 0.723 \\
\hline $\mathrm{II}+\mathrm{III}$ & SJ-MW & 1506 & 575 & $(-267$ & 3280) & 2.62 & 0.218 \\
\hline
\end{tabular}

Table 11. Tukey's pairwise comparison for ITS test modulus, MPa.

\begin{tabular}{cccccccc}
\hline Stage & $\begin{array}{c}\text { Difference } \\
\text { of Levels }\end{array}$ & $\begin{array}{c}\text { Difference of } \\
\text { Means, MPa }\end{array}$ & $\begin{array}{c}\text { SE of Difference, } \\
\mathbf{M P a}\end{array}$ & $\mathbf{9 0 \%}$ CI, MPa & $\begin{array}{c}\text { T-Value } \\
\boldsymbol{p} \text {-Value }\end{array}$ \\
\hline II + III & MW-P1 & 423.3 & 62.1 & $(231.7 ;$ & $614.8)$ & 6.81 & 0.000 \\
II + III & MW-T1 & 407.3 & 71.7 & $(186.1 ;$ & $628.5)$ & 5.68 & 0.001 \\
II + III & MW-T2 & 398.2 & 65.5 & $(196.3 ;$ & $600.1)$ & 6.08 & 0.000 \\
II + III & MW-P2 & 174.7 & 60.0 & $(-10.4 ;$ & $359.7)$ & 2.91 & 0.135 \\
II + III & VJ-MW & -136.5 & 65.5 & $(-338.5 ;$ & $65.4)$ & -2.08 & 0.462 \\
II + III & IR-MW & 78.3 & 65.5 & $(-123.7 ;$ & $280.2)$ & 1.19 & 0.922 \\
II + III & SJ-MW & 41.9 & 71.7 & $(-179.3 ;$ & $263.1)$ & 0.58 & 0.999 \\
\hline
\end{tabular}

To summarize this stage of the testing plan it should be emphasized that midtemperature $\left(0^{\circ} \mathrm{C}\right)$ strength is not less important than low-temperature, sub-zero performance. Test results showed that the microwave joint heating technique resulted in overall performance comparable to infrared joint heated technique. The range of test results was similar as regards stiffness modulus, tensile strength and ultimate strain. The material type joints, namely the vertical and skewed joints, performed almost the same. On the other hand, the sealing materials in $0{ }^{\circ} \mathrm{C}$ became softer and resulted in relatively lower ultimate strength and low modulus. It can be concluded that applied sealing ma- 
terials, especially P1 and T1, were soft enough to dilate the joint but without playing role in bearing the wheel loads from road traffic. These materials are meant to seal the joint, which is correct, but this solution needs to incorporate an extra material and extra installation process.

In all joint types, the uniformity of ITS test results was not so clear as in the case of TSRST test results, probably due to difficulties with discovering the exact location of the joint, which could affect the test result, together with the smaller size of the testing specimens, which could also affect the test result range. It is worth mentioning that ITS test results at $0{ }^{\circ} \mathrm{C}$ for cylindrical specimens of typical binder or wearing course asphalt vary between 4000 and $5000 \mathrm{kPa}$, so it also can be concluded that $\mathrm{SJ}$ joint type test results were very close to those values.

\subsubsection{Semi-Circular Bending SCB}

SCB specimens are cylindrical shaped, $150 \mathrm{~mm}$ in diameter. Typically, specimens of this type have an additional notch, the groove that is cut perpendicularly to the specimen diameter and is meant to weaken the specimen cross-section and localize the crack growth location. In the case of specimens cut from the longitudinal joints, this step was omitted, while the joint itself was a weak point of a specimen, and was the most probable location of crack initiation during testing. Example photos of specimens were shown in Figure 10.

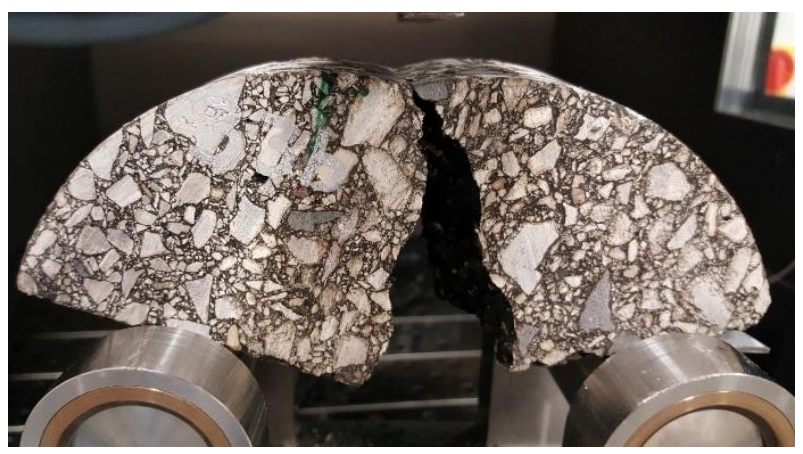

(a)

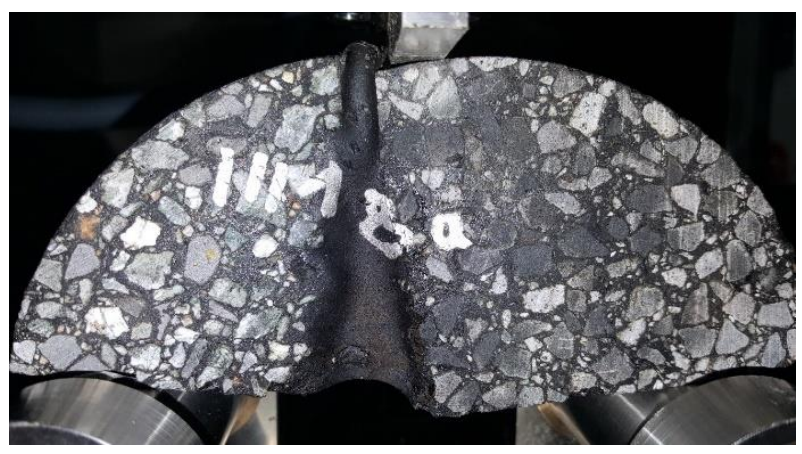

(b)

Figure 10. (a) Semi-cylindrical specimens after bending test MW; (b) Semi-cylindrical specimens after bending test T1.

In the case of stage II of the experiment, untreated and treated type joints performed better than sealed joints. MW joints together with VJ and IR performed better than P2, T1 or T2 while SJ was not present in the test at all, as all specimens failed to reach the testing stage. In stage III MW specimens outperformed rest of specimens, especially P1, P2 or $\mathrm{T} 1$ and T2. Results are shown in Figure 11. Tukey's pairwise comparison statistics are presented in Table 12.

The SCB test protocol uses $150 \mathrm{~mm}$ cores. This size of specimen contributed in successful localizing the longitudinal joint in the pavement, thus more specimens were suitable for testing in the laboratory. The microwave-assisted joint showed good performance in stage II tests and an excellent performance in stage III tests. While the variability of test results in stage II was similar in case of all types of unsealed joint construction techniques, in stage III it appeared that the microwave construction technique performed the best in terms of the range of results and ultimate stress level.

Two factors were differentiating the ultimate stress levels presented in stage II and III. These were the differences in asphalt properties used in wearing course and binder course and the presence of sealing material. One can expect that sealed joints specimens, despite representing low stiffness and low tensile strength during SCB tests, were still sealed after the test, which makes the discontinuity in asphalt still waterproof, thus advantageous. 


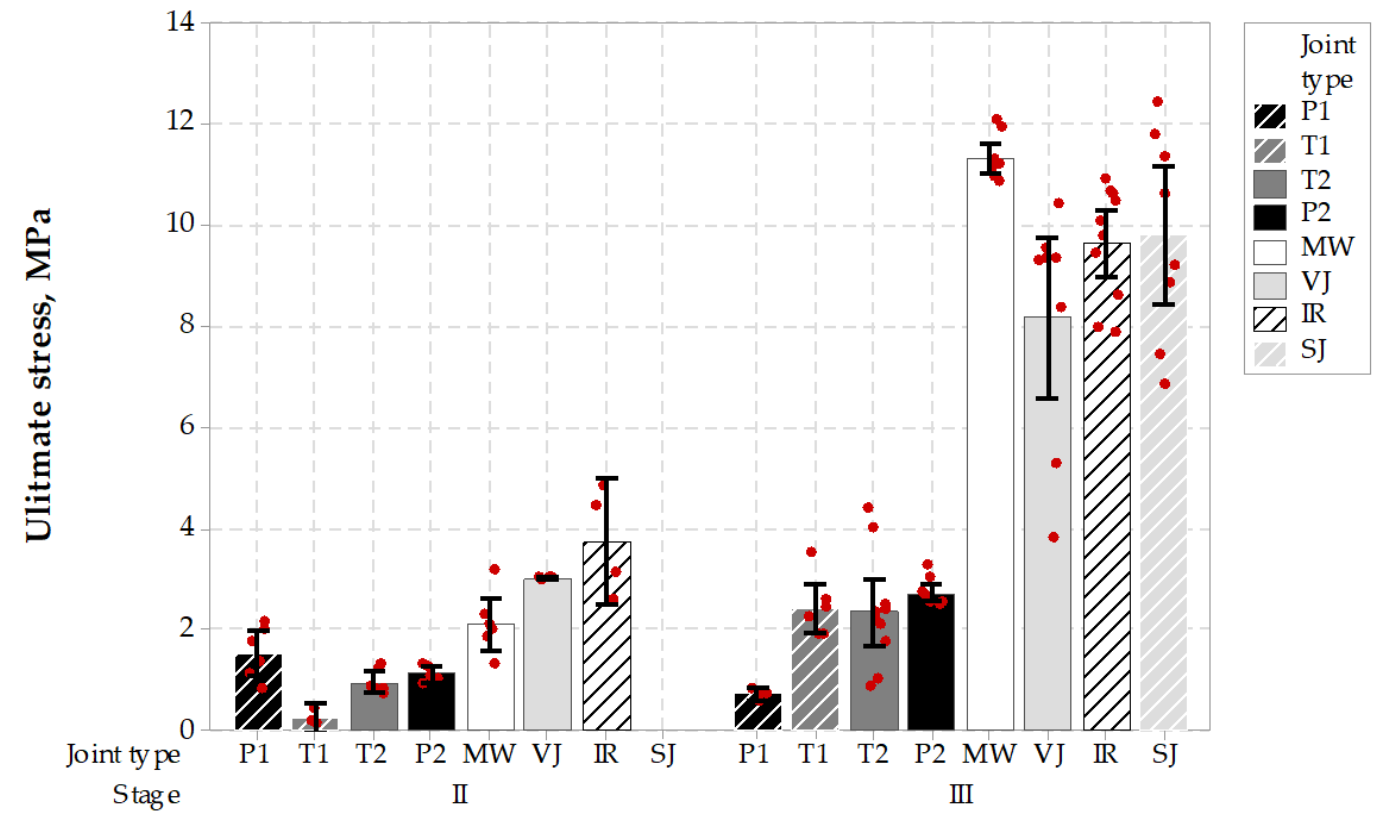

Individual standard deviations are used to calculate the intervals ( $p=90 \%$ ).

Figure 11. Semi-circular bending test results (the higher, the better).

Table 12. Tukey's pairwise comparison for SCB test, ultimate stress.

\begin{tabular}{|c|c|c|c|c|c|c|c|}
\hline \multirow{2}{*}{$\begin{array}{l}\text { Stage } \\
\mathrm{II}+\mathrm{III}\end{array}$} & \multirow{2}{*}{$\begin{array}{c}\begin{array}{c}\text { Difference } \\
\text { of Levels }\end{array} \\
\text { MW-P1 }\end{array}$} & \multirow{2}{*}{$\begin{array}{c}\text { Difference of } \\
\text { Means, } \mathbf{M P a}\end{array}$} & \multirow{2}{*}{$\begin{array}{c}\text { SE of Difference, } \\
\mathbf{M P a}\end{array}$} & \multicolumn{2}{|c|}{$90 \% \mathrm{CI}, \mathrm{MPa}$} & \multirow{2}{*}{$\begin{array}{c}\text { T-Value } \\
13.3\end{array}$} & \multirow{2}{*}{$\begin{array}{c}\begin{array}{c}\text { Adjusted } \\
\boldsymbol{p} \text {-Value }\end{array} \\
0.000\end{array}$} \\
\hline & & & & (6.006; & $9.266)$ & & \\
\hline $\mathrm{II}+\mathrm{III}$ & MW-T1 & 6.5 & 0.5 & (5.025; & $7.940)$ & 12.6 & 0.000 \\
\hline $\mathrm{II}+\mathrm{III}$ & MW-T2 & 6.2 & 0.4 & (4.900; & $7.406)$ & 13.9 & 0.000 \\
\hline $\mathrm{II}+\mathrm{III}$ & MW-P2 & 5.8 & 0.5 & (4.425; & 7.091) & 12.3 & 0.000 \\
\hline $\mathrm{II}+\mathrm{III}$ & MW-VJ & 2.0 & 0.5 & (0.654; & $3.328)$ & 4.2 & 0.002 \\
\hline $\mathrm{II}+\mathrm{III}$ & MW-IR & 0.8 & 0.5 & $(0.543$ & $2.056)$ & 1.7 & 0.718 \\
\hline $\mathrm{II}+\mathrm{III}$ & MW-SJ & -1.9 & 0.7 & $(-3.890$ & $0.033)$ & -2.8 & 0.113 \\
\hline
\end{tabular}

\subsubsection{Density Measurements}

The last part of the evaluation of different joint techniques was the testing of the bulk density of specimens. Measurements were conducted in the saturated, surface dry condition. It can be mentioned that the specimens' bulk density was measured on specimens that were already tested mechanically and split into half. Both specimen sub-parts were tested individually. The screening concluded on the sub-parts resulted in the rejection of some of the specimens due to the mechanical disintegration. Test results are shown through the compaction degree where the bulk density was divided by bulk reference Marshall density for the mixes and is shown in Figure 12.

The bulk density measurements concluded that in the case of stage II, the average specimen compaction degree for MW, IR, P2, P1 and VJ was in the same statistical group. Lower results for T2 and T1 were obtained, but the differences are not statistically significant. In case of the results from stage III, MW-treated joint results were significantly higher than the results from the other joint types. It can be concluded that asphalt pavement characterized itself with a higher degree of compaction and lower air-voids level comparing to other joint types. The sealing materials used in sealed joint types could lower the density measurements as it was not fully discarded from the specimen and the density of sealing material was significantly lower than the density of the asphalt specimen. But inarguably the MW joint type achieved the highest level of compaction, which is expected from the process of forming of durable joints in the asphalt pavements. Fisher's pairwise statistics are shown in Table 13. 


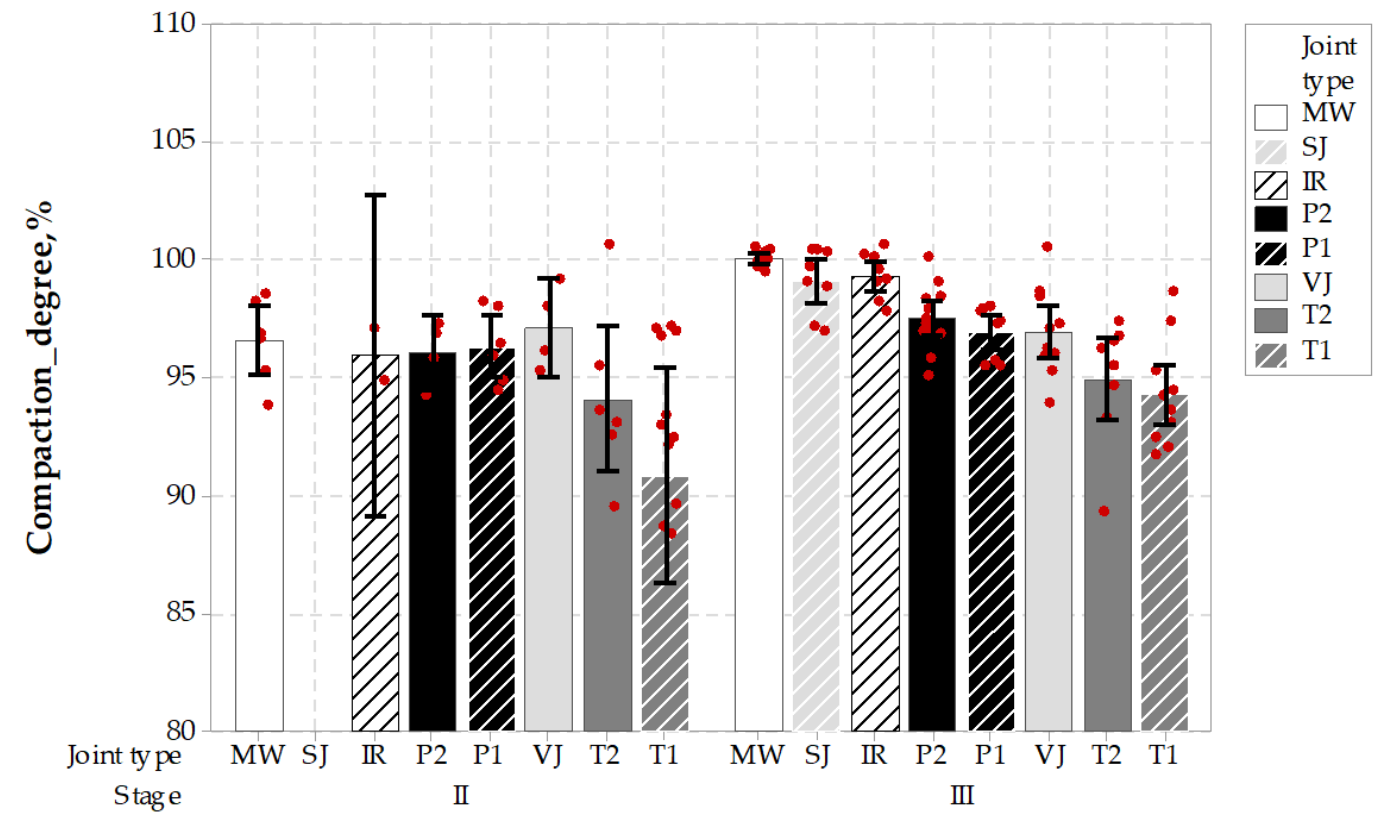

Individual standard deviations are used to calculate the intervals ( $p=90 \%$ ).

Figure 12. Compaction degree test results of specimens taken from longitudinal joints.

Table 13. Fisher's pairwise comparison for density test, bulk density SSD, $\mathrm{Mg} / \mathrm{m}^{3}$.

\begin{tabular}{cccccccc}
\hline Stage & $\begin{array}{c}\text { Difference of } \\
\text { Levels }\end{array}$ & $\begin{array}{c}\text { Difference of } \\
\text { Means }\end{array}$ & SE of Difference & $\mathbf{9 0 \%}$ CI & $\begin{array}{c}\text { T-Value } \\
\boldsymbol{p} \text {-Value }\end{array}$ \\
\hline III & SJ-MW & -0.0423 & 0.0249 & $(-0.0838 ;$ & $-0.0007)$ & -1.70 & 0.095 \\
III & IR-MW & -0.0431 & 0.0249 & $(-0.0847 ;$ & $-0.0015)$ & -1.73 & 0.088 \\
III & P2-MW & -0.0884 & 0.0228 & $(-0.1264 ;$ & $-0.0504)$ & -3.89 & 0.000 \\
III & P1-MW & -0.1041 & 0.0249 & $(-0.1457 ;$ & $-0.0625)$ & -4.18 & 0.000 \\
III & VJ-MW & -0.1037 & 0.0236 & $(-0.1431 ;$ & $-0.0642)$ & -4.38 & 0.000 \\
III & T2-MW & -0.1525 & 0.0249 & $(-0.1941 ;$ & $-0.1109)$ & -6.12 & 0.000 \\
III & T1-MW & -0.1694 & 0.0236 & $(-0.2088 ;$ & $-0.1299)$ & -7.16 & 0.000 \\
\hline
\end{tabular}

3.3. Crack Repair

\subsubsection{General}

After finishing the repair process described in Section 2.6, there were also specimens taken from the repaired pavement for ITS and SCB tests. The same statistical assumptions were made for the repaired crack tests. The repair process turned out to be fully successful, as the cracked pavement was healed on its full depth, which is presented in Figure 13.

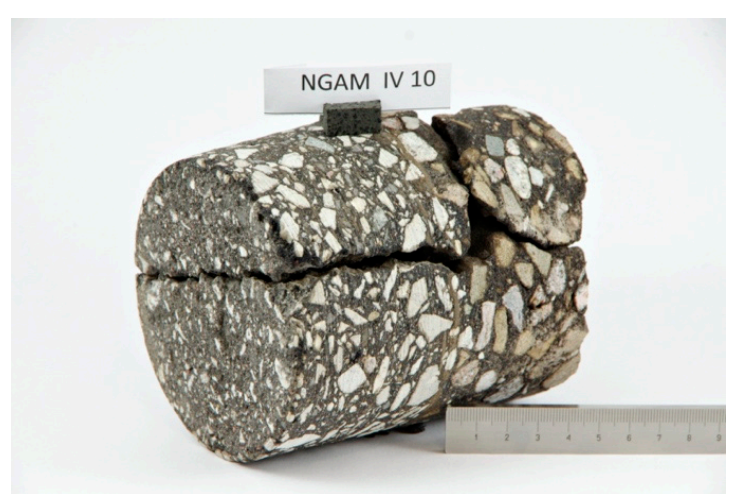

(a)

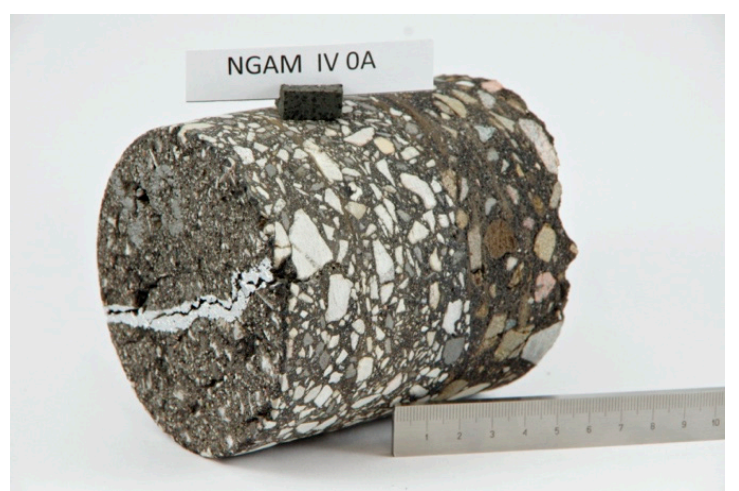

(b)

Figure 13. Cont. 


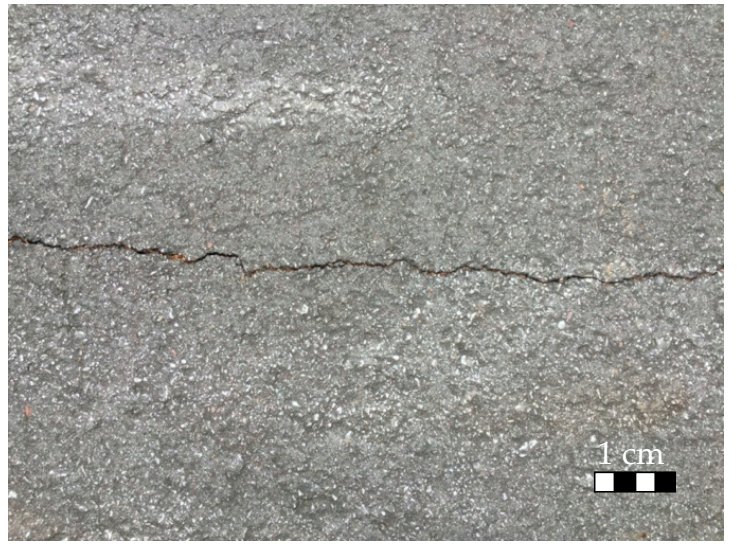

(c)

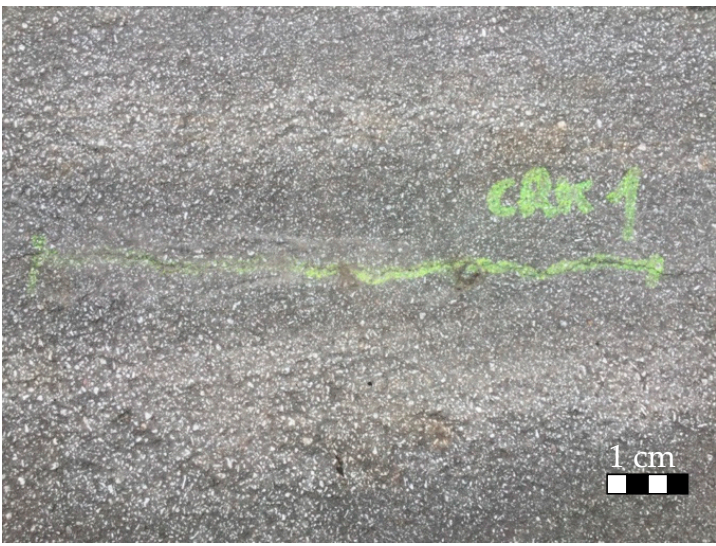

(d)

Figure 13. (a) Illustration of real-scale test section microwave-assisted asphalt pavement repair (cores were taken from nearby locations), core from the pavement before MW treatment; (b) Core from the pavement treated with MW; (c) Cracked pavement before MW repair (crack width ca. $5 \mathrm{~mm}$, crack depth-12 cm, full pavement depth, (d) Cracked pavement after MW repair.

\subsubsection{Indirect Tensile Strength ITS}

All $100 \mathrm{~mm}$ specimens were successfully cored from the repaired pavement and they were subjected to indirect tension tests. Obtained results (presented in Figure 14) show that relatively high indirect tensile strength was obtained, almost equal to results obtained on longitudinal joints test section, stage II and III. Also, very high indirect tension modulus was obtained, even of higher value than on stage II and III tests. On the other hand, the ultimate strain was lower than that achieved on specimens from stage II and III, probably because of lower binder content in the tested pavement and absence of polymer-modified bitumen used in mixes from stage II and III.
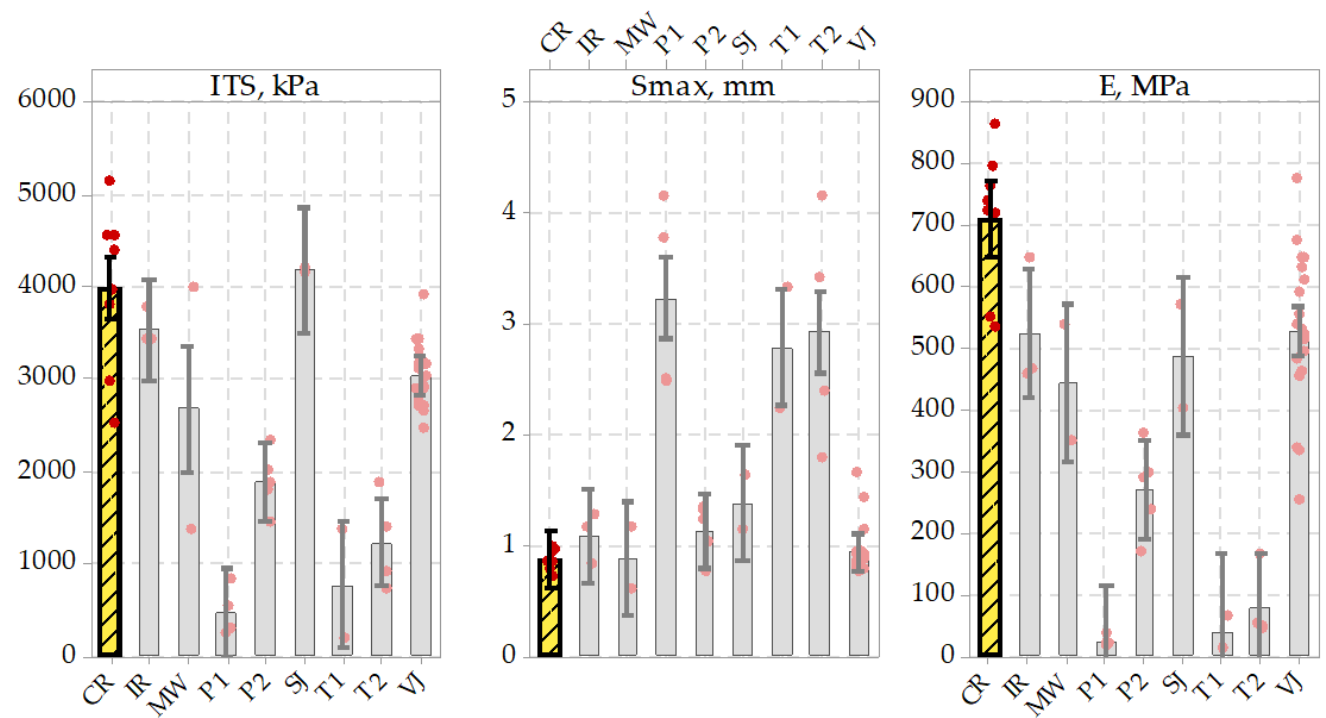

\section{Joint type}

The pooled standard deviation is used to calculate the confidence intervals ( $p=90 \%$ ).

Figure 14. Indirect tension test results on specimens taken from the repaired crack.

The formulated statistical hypothesis asked if achieved test results are higher than zero (for cracked pavement). All tests confirmed that achieved mean values of ITS, Smax and $\mathrm{E}$ were significantly greater than zero (at $p<0.001)$. 


\subsubsection{Semi-Circular Bending SCB}

Also, all $150 \mathrm{~mm}$ cores for semi-circular bending test were successfully taken from the repaired crack area. After cutting the specimens in half, they were tested in the same conditions as specimens taken from longitudinal joints. The results were positive, and an average of 1.8 MPa was achieved (Figure 15). The results were similar to results obtained in stage II of the tests on specimens taken from longitudinal joints. So this experiment was successful. The following statistical hypothesis was formulated: achieved test results are higher than zero (for cracked pavement). The test confirmed that the achieved mean value of ultimate stress was significantly greater than zero (at $p<0.001$ ).

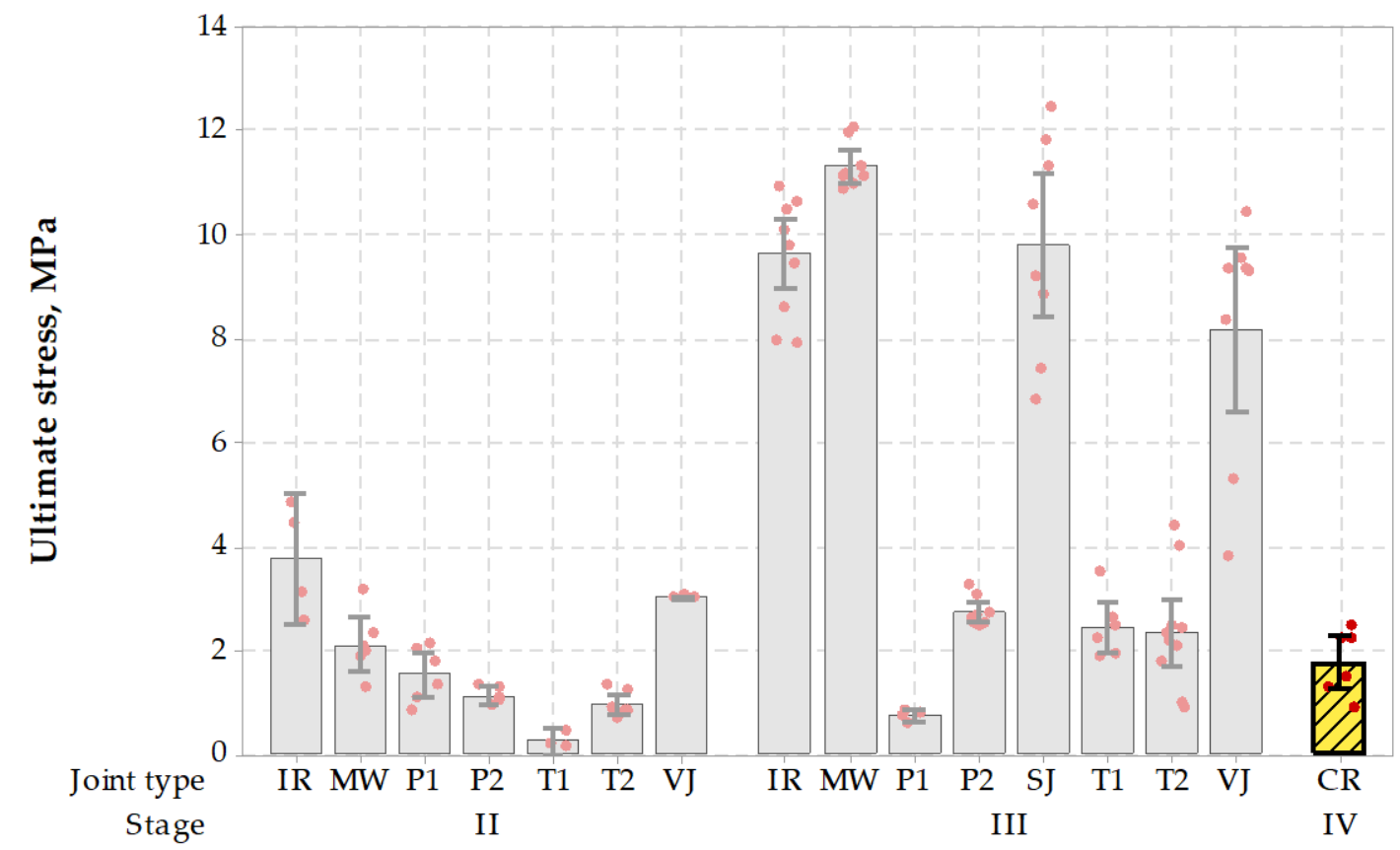

Individual standard deviations are used to calculate the intervals $(p=90 \%)$.

Figure 15. Semi-circular bending test results of the specimens from the repaired crack (CR, stage IV) compared to longitudinal joints (the higher, the better).

\subsubsection{Summary of the Crack Repair Process}

The described process can be summarized by stating that microwave heating for crack healing is a very promising method. Using this repair technique, there is no need to use either extra sealing materials or perform some noisy cutting operations. The only needed media was the power supply. Every step of this operation was performed with the use of electrical equipment. Considering good, "green" power supply such as solar systems or wind turbines, it can be said that this technology can be described as ecological repair technology. The phenomenon of crack healing was based on the physical process of heating aggregates and bituminous binder, followed by thorough cleaning of the crack faces. The microwave heating made it possible to slightly rearrange the mixture within the area of the cracked asphalt layers and recompact it. The final effect was the regained homogeneity, integrity and stress transferring ability of the asphalt layer. The integrity of the crack made pavement waterproof again, so the possibility of water drainage through the pavement was reduced and deterioration of subbase or subgrade was stopped. The repair process can be repeated in case of additional cracking. Additional sealing materials also could be used and microwave heating could promote the better connection of materials. Further development of this repair method should be continued. 


\subsection{Bitumen}

Test specimens after several stages of aging were tested in Dynamic Shear Rheometer in a wide range of frequency and temperature. After that master curves were built and rheological parameters R-value and G-R parameter were calculated. Calculated parameters are presented in Figures 16 and 17.

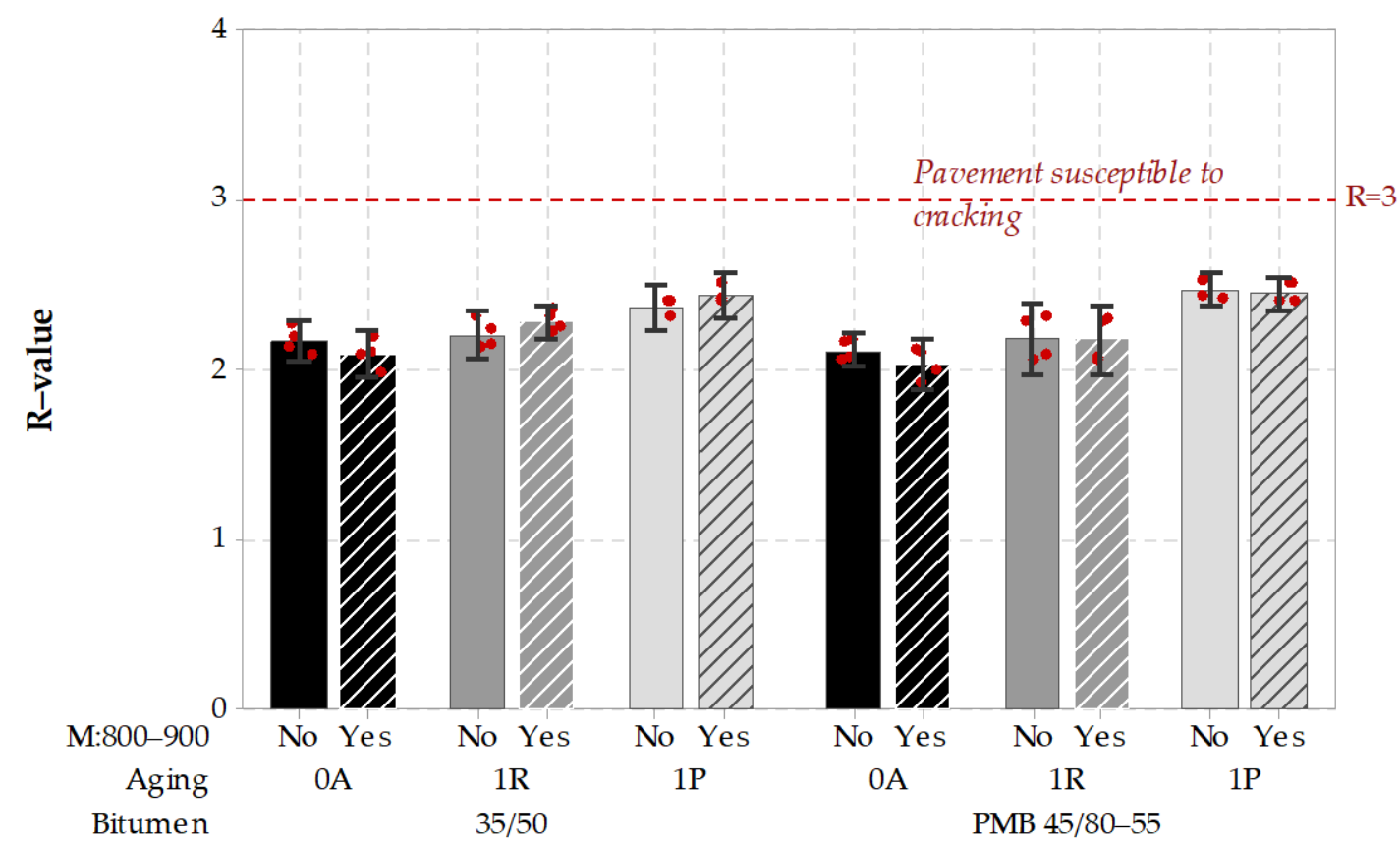

Individual standard deviations are used to calculate the intervals ( $p=95 \%$ ).

Figure 16. Interval plot of R-value of bitumen obtained in different aging conditions (the higher, the worse).

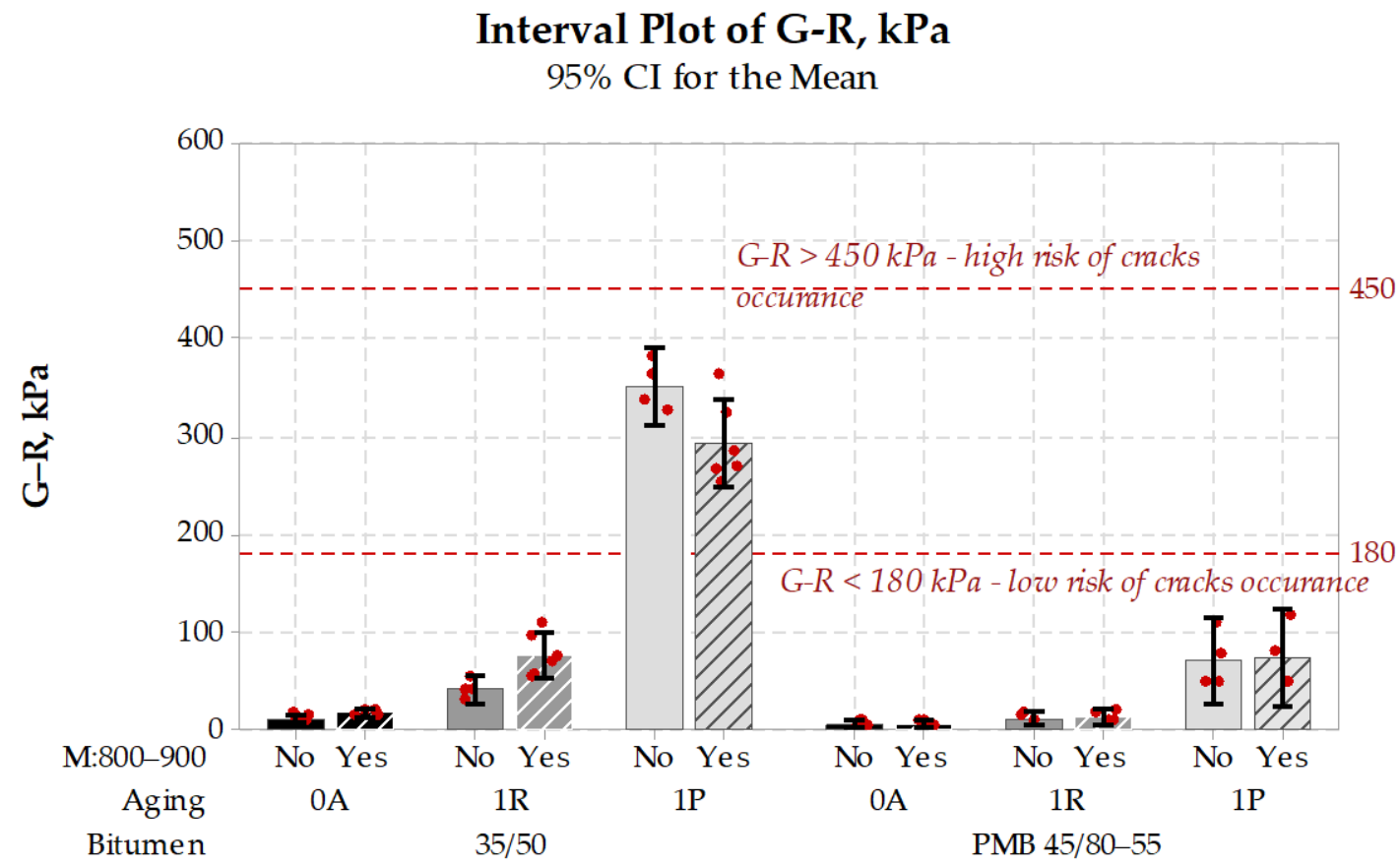

Individual standard deviations are used to calculate the intervals ( $p=95 \%$ ).

Figure 17. Interval plot of G-R parameter of bitumen obtained in different aging conditions (the higher, the worse). 
The R-value of both tested bitumen were under 3, so none of the tested specimens presented the potential pavement susceptibility to cracking. Changes in R-value following traditional $1 \mathrm{R}$ and $1 \mathrm{P}$ aging protocols were of significant importance, while the influence of the microwave aging was neither engineering nor statistically important. Higher differences occurred after determining the G-R parameter. Traditional aging protocols influenced G-R parameter of neat bitumen more significantly than PMB. Mostly all cases of aging resulted in G-R parameter not exceeding $180 \mathrm{kPa}$, which can be interpreted as a low risk of pavement cracking. Only the neat $35 / 50$ bitumen aged according to $1 \mathrm{P}$ protocol resulted in a relatively high $350 \mathrm{kPa}$ mean level, and surprisingly after treatment of aged specimens with the microwaves, G-R parameter value was reduced by $50 \mathrm{kPa}$. According to G-R parameter description, this reduction can be interpreted as decrease of pavement possible susceptibility to cracking. This microwave-induced reduction of G-R parameter should be further investigated on wider range of bitumen types.

To sum up the presented bitumen test results, no negative influence of microwaves on bitumen properties in R-value and G-R parameter was found. Based on these test results, it can be concluded that microwave heating should have no harm on asphalt properties, which could affect the pavement cracking susceptibility. There is even a possibility of reducing the pavement cracking risk with the use of microwave heating, and this finding should be further investigated.

\section{Discussion}

This research was focused on the evaluation of microwave-assisted joint-forming technique in comparison to traditional techniques. Another part of this research was a demonstration of the application of microwave heating technique on the cracked pavement to repair the crack. Joints and repaired cracks were evaluated through mechanical tests and quality tests. Longitudinal joint-forming technique assisted with microwave heating (MW) was placed in the group of other vertical treated or untreated joints, bringing the same or better tensile strength in different temperature ranges. Better compaction of asphalt mixture in the vicinity of longitudinal joints resulted in lower air-voids content and supported the increase of sensitivity to water and frost, homogeneity and flexibility. It also supported the tensile strength increase of the joint, which resulted in good joint performance in around $0{ }^{\circ} \mathrm{C}$ and subzero temperatures. In the group of vertical treated joints technique, the microwave heating advances over infrared heating, as it does not affect the bituminous materials the way the heat-transfer based technique does. Microwave energy does not overheat the surface of the bituminous mixture (and bitumen), while the infrared heating is very likely to do so. Comparing the two groups of vertical-treated and vertical-untreated joints to vertical sealed joints, it can be concluded that effectiveness of sealing in both groups was maintained but in a different way. Material sealed joints were softer and less stiff, so they characterized themselves by higher extensibility, while the joint was still sealed. On the opposite side, the treated vertical joints made pavement almost seamless, what was confirmed by high tensile strength values, but also low deflection resulting in high modulus values. The most promising finding of the microwave-assisted joint was a better uniformity and compaction of the asphalt layer along the joint. Tested bulk density of specimens and resulting compaction degree were significantly higher than other types of joints. The microwave applicator was able to gain the operational speed of $0.1-1 \mathrm{~m} / \mathrm{min}$ (depending on the type of used aggregates). The operational speed is the key factor for the further development of the applicator design. Typical operational speeds during asphalt paving reach $60 \mathrm{~m} / \mathrm{min}$, so the proper design of the microwave applicator should account for the adequate performance.

In case of microwave-heated cracking repair, the experiment was successful as cracked pavement regained its integrity on full depth and specimens taken from repaired crack were capable of transferring the tensile loads. The success of the crack repair was based on the possibility of volumetric asphalt mix reheating. Reheated asphalt mix characterized itself with the workability high enough to redistribute aggregates and enable the further 
compaction of the asphalt mix in the crack vicinity. The total depth of crack repair was ca. $10 \mathrm{~cm}$, but numerical simulations presented in publication [43] suggest that depth of $15-20 \mathrm{~cm}$ could be easily reached. The crack heating operational speed was in this case $0.1 \mathrm{~m} / \mathrm{min}$, so $1 \mathrm{~m}$ crack could be repaired within 10-20 min, including recompaction of the pavement.

There was a blistering phenomenon observed during the heating of longitudinal joints and cracks healing. The phenomenon was significantly more intense on older pavement, which seemed to be more saturated with water compared to a new dry pavement structure.

There are also some challenges of microwave heating to be considered. It must be stated that not every road material is susceptible to dielectric heating in the same way. Even in this research project tested materials characterized themselves with varied reaction to microwave heating, thus resulting in the different time needed to heat the asphalt layer to a suitable temperature. Further research should be concluded to achieve optimum power/time dielectric heating parameters.

\section{Conclusions}

It can be concluded that microwave heating is a promising method of assisting the construction or repair process of pavement. It does not need to use additional sealing materials, and it can be powered by a green source of energy. The following conclusions were stated in the article:

- MW joints were durable in TSRST test, no negative influence on low-temperature cracking was concluded; even though the maximum stresses were higher than in case of sealed joints, crack temperature level was still on a satisfactory level,

- MW joints were in the middle class for the ITS test, while E modulus presented the highest level in the test set,

- $\quad$ MW joints were significantly in the best class of the ultimate stress test results as regards the wearing course (stage III); it showed an overall significant advantage over material type joints while being the best in the class of the treated and untreated joints,

- the density measurements showed most important MW joint technique advantage over other tested techniques, presenting the highest average value and lowest range of single results; the difference was not significant, but one of the reasons was high standard deviations achieved in case of the other jointing techniques,

- MW crack repair technique brought good results should be observed in a longer period; what is important, the repair process can be repeated according to needs,

- Bitumen tests did not bring any negative conclusions as regards bitumen properties and their predicted influence on cracking susceptibility of asphalt pavement.

The microwave-assisted pavement construction process is a promising way of road works development. The sealing process itself could be easily incorporated and adopted in standard paving equipment. In this article, it was concluded that microwave heating resulted in the formation of longitudinal joints that were durable and mechanically resistant in a wide range of temperatures. What was most important, the pavement in the close vicinity of the microwave-heated joint characterized itself with higher density and compaction level, compared to other joint-forming techniques. This very promising observation could be a significant improvement over standard joint formation techniques and should be further tested. It should be also mentioned that no additional material has to be used and no non-renewable resources were needed. This technique should be tested on a wider scale in real roadwork conditions. In the time of $\mathrm{CO}_{2}$ emission reduction needs, any technique that potentially does not need to use non-renewable energy should be considered for use. The first trials of using the microwave technique as a heat source were considered in early 1970s, developed in the ' 80 s, further tested in ' 90 s but never came to regular use. If we consider that electrification comes to our everyday life, the microwave heating solutions have never been so close for implementation and commercialization. 
Author Contributions: Conceptualization, M.M., A.Z. and D.S.; methodology, M.M., A.Z., B.S. and D.S.; validation, M.M. and A.Z.; formal analysis, M.M., D.M. and A.Z.; investigation, M.M., B.S., T.K. and R.R.; resources, M.M., A.Z., B.S., T.K. and D.M.; data curation, M.M. and R.R.; writingoriginal draft preparation, M.M. and D.M.; writing-review and editing, A.Z.; visualization, M.M.; supervision, A.Z. and D.S.; project administration, M.M.; funding acquisition, M.M. and D.S. All authors have read and agreed to the published version of the manuscript.

Funding: This research was cofounded by the Polish National Center for Research and Development [NCBR, grant no PBS2/B3/19/2013].

Institutional Review Board Statement: Not applicable.

Informed Consent Statement: Not applicable.

Data Availability Statement: Not applicable.

Acknowledgments: Authors would kindly acknowledge Wojciech Bańkowski, Marcin Gajewski, Renata Horodecka Krzysztof Mirski, Jacek Biegajski, Artur Ciećwierz, Dariusz Jasiński and Wojciech Kowalczyk from Pavement Technology Division, IBDiM, for patience and courage in dealing with tests, trials and microwaves, partners from QWED Sp. z o.o., Wojciech Gwarek, Małgorzata Celuch, Janusz Rudnicki, Marzena Olszewska for providing necessary knowledge and equipment for the microwave applicator design, colleagues from the road industry Leszek Wydra, Jacek Krzemiński, Mariusz Chrabaszzz, Andrzej Stachurski and Robert Bałecki for help and advice in technology and construction of test field and road designers Maciej Kryński and Grzegorz Dąbrowski for the test field design and advice.

Conflicts of Interest: The authors declare no conflict of interest. The funders had no role in the design of the study, in the collection, analyses, or interpretation of data, in the writing of the manuscript, or in the decision to publish the results.

\section{Appendix A}

The appendix contains additional material characteristics, which might be useful for evaluation of the test results. Tables A1-A4 contain parameters of the aggregates used to design the asphalt mix. Table A5 contains parameters of bituminous binders. Bitumen were supplied by LOTOS company.

Table A1. Properties of basalt aggregate used in "B" type mixes (results by the producer).

\begin{tabular}{|c|c|c|c|c|c|}
\hline Properties (Standard) & Basalt 0/2 & Basalt 2/5 & Basalt 5/8 & Basalt 8/11 & Basalt 11/16 \\
\hline Aggregate size d/D (mm), EN 933-1 & $0 / 2$ & $2 / 5$ & $5 / 8$ & $8 / 11$ & $11 / 16$ \\
\hline Aggregate distribution category (mm), EN 933-1 & $\mathrm{G}_{\mathrm{c}} 85$ & $\mathrm{G}_{\mathrm{c}} 90 / 10$ & $\mathrm{G}_{\mathrm{C}} 90 / 10$ & $\mathrm{G}_{\mathrm{c}} 90 / 10$ & $\mathrm{G}_{\mathrm{c}} 90 / 10$ \\
\hline Aggregate tolerance category (mm), EN 933-1 & $\mathrm{G}_{\mathrm{TC}} 20$ & $\mathrm{G} 25 / 15$ & $\mathrm{G} 25 / 15$ & $\mathrm{G} 25 / 15$ & $\mathrm{G} 25 / 15$ \\
\hline Aggregate apparent density $\left(\mathrm{Mg} / \mathrm{m}^{3}\right)$, EN 1097-6 & $\rho_{\mathrm{a}} 3.00$ & $\rho_{\mathrm{a}} 3.01$ & $\rho_{\mathrm{a}} 3.02$ & $\rho_{\mathrm{a}} 3.01$ & $\rho_{\mathrm{a}} 3.01$ \\
\hline Agg. oven dried density $\left(\mathrm{Mg} / \mathrm{m}^{3}\right)$, EN 1097-6 & $\rho_{\text {rd }} 2.84$ & $\rho_{\text {rd }} 2.89$ & $\rho_{\text {rd }} 2.90$ & $\rho_{\text {rd }} 2.89$ & $\rho_{\text {rd }} 2.89$ \\
\hline Agg. saturated surface dried dens. $\left(\mathrm{Mg} / \mathrm{m}^{3}\right)$, EN 1097-6 & $\rho_{\text {ssd }} 2.90$ & $\rho_{\text {ssd }} 2.93$ & $\rho_{\text {ssd }} 2.94$ & $\rho_{\text {ssd }} 2.93$ & $\rho_{\mathrm{ssd}} 2.93$ \\
\hline Shape index (mass \%), EN 933-4 & - & $\mathrm{SI}_{15}$ & $\mathrm{SI}_{15}$ & $\mathrm{SI}_{15}$ & $\mathrm{SI}_{15}$ \\
\hline Flakiness index (mass \%), EN 933-3 & - & $\mathrm{FI}_{10}$ & $\mathrm{FI}_{10}$ & $\mathrm{FI}_{10}$ & $\mathrm{FI}_{10}$ \\
\hline Fines content (mass \%), EN 933-1 & 16 & 2 & 2 & 2 & 2 \\
\hline Fines quality (methylene blue value), EN 933-9 & $\mathrm{MB}_{\mathrm{f}} 10$ & - & - & - & - \\
\hline Bitumen affinity (rotating bottle test, \%) & - & $6 \mathrm{~h}-90 \%$ & $6 \mathrm{~h}-90 \%$ & $6 \mathrm{~h}-90 \%$ & $6 \mathrm{~h}-90 \%$ \\
\hline EN 12697-11 & & $24 \mathrm{~h}-70 \%$ & $24 \mathrm{~h}-70 \%$ & $24 \mathrm{~h}-70 \%$ & $24 \mathrm{~h}-70 \%$ \\
\hline $\begin{array}{l}\text { Percentage of crushed and broken surface (mass \%), } \\
\text { EN 933-5 }\end{array}$ & - & $\mathrm{C}_{100 / 0}$ & $\mathrm{C}_{100 / 0}$ & $\mathrm{C}_{100 / 0}$ & $\mathrm{C}_{100 / 0}$ \\
\hline Los-Angeles index, EN 1097-2 & - & 15 & 15 & 15 & 15 \\
\hline Polishing stone value, EN 1097-8 & - & 48 & 48 & 48 & 48 \\
\hline Aggregate abrasion value, EN 1097-9 & - & 10 & 10 & 10 & 10 \\
\hline Micro-Deval index, EN 1097-1 & - & 15 & 15 & 15 & 15 \\
\hline \multirow[t]{2}{*}{ Resistance to thermal shock, EN 1367-5 } & - & $\mathrm{I}_{\%} 1.5$ & $\mathrm{I}_{\%} 1.5$ & $\mathrm{I}_{\%} 1.5$ & $\mathrm{I}_{\%} 1.5$ \\
\hline & - & $\mathrm{V}_{\mathrm{LA}} 5$ & $\mathrm{~V}_{\mathrm{LA}} 5$ & $\mathrm{~V}_{\mathrm{LA}} 5$ & $\mathrm{~V}_{\mathrm{LA}} 5$ \\
\hline Water absorption 24 h, EN 1097-6 & 1.9 & 1.3 & 1.3 & 1.3 & 1.3 \\
\hline Resistance to freezing and thawing, EN 1367-1 & - & 0.2 & 0.2 & 0.2 & 0.2 \\
\hline Sand angularity index, EN 933-6 & $\mathrm{E}_{\mathrm{cs}} 38$ & - & - & - & - \\
\hline "Sonnenbrand" of basalt, EN 1367-3 & - & $\mathrm{SB}_{\mathrm{LA}}$ & $\mathrm{SB}_{\mathrm{LA}}$ & $\mathrm{SB}_{\mathrm{LA}}$ & $\mathrm{SB}_{\mathrm{LA}}$ \\
\hline
\end{tabular}


Table A2. Properties of gabbro aggregate used in "G" type mixes (results by the producer).

\begin{tabular}{|c|c|c|c|}
\hline Properties (Standard) & Gabbro $0 / 2$ & Gabbro 2/5 & Gabbro $4 / 8$ \\
\hline Aggregate size d/D (mm), EN 933-1 & $0 / 2$ & $2 / 5$ & $4 / 8$ \\
\hline Aggregate distribution category (mm), EN 933-1 & $\mathrm{G}_{\mathrm{c}} 85$ & $\mathrm{G}_{\mathrm{C}} 90 / 15$ & $\mathrm{G}_{\mathrm{c}} 90 / 10$ \\
\hline Aggregate tolerance category (mm), EN 933-1 & $\mathrm{G}_{\mathrm{TC}} 10$ & $\mathrm{G}_{25 / 15}$ & $\mathrm{G}_{25 / 15}$ \\
\hline Aggregate apparent density $\left(\mathrm{Mg} / \mathrm{m}^{3}\right), \mathrm{EN} 1097-6$ & $\rho_{\mathrm{a}} 2.93$ & $\rho_{\mathrm{a}} 2.99$ & $\rho_{\mathrm{a}} 2.98$ \\
\hline Agg. oven dried density $\left(\mathrm{Mg} / \mathrm{m}^{3}\right)$, EN 1097-6 & $\rho_{\text {rd }} 2.83$ & $\rho_{\text {rd }} 2.95$ & $\rho_{\text {rd }} 2.96$ \\
\hline Agg. saturated surface dried dens. $\left(\mathrm{Mg} / \mathrm{m}^{3}\right)$, EN 1097-6 & $\rho_{\mathrm{ssd}} 2.87$ & $\rho_{\mathrm{ssd}} 2.97$ & $\rho_{\text {ssd }} 2.97$ \\
\hline Shape index (mass \%), EN 933-4 & - & $\mathrm{SI}_{20}$ & $\mathrm{SI}_{15}$ \\
\hline Flakiness index (mass \%), EN 933-3 & - & $\mathrm{FI}_{20}$ & $\mathrm{FI}_{15}$ \\
\hline Fines content (mass \%), EN 933-1 & 10 & 1 & 1 \\
\hline Fines quality (methylene blue value), EN 933-9 & $\mathrm{MB}_{\mathrm{f}} 10$ & - & - \\
\hline Bitumen affinity (rotating bottle test, $\%$ ) & - & $6 \mathrm{~h}-62 \%$ & $6 \mathrm{~h}-62 \%$ \\
\hline EN 12697-11 & & $24 \mathrm{~h}-18 \%$ & $24 \mathrm{~h}-18 \%$ \\
\hline $\begin{array}{l}\text { Percentage of crushed and broken surface (mass \%), } \\
\text { EN 933-5 }\end{array}$ & - & $\mathrm{C}_{100 / 0}$ & $\mathrm{C}_{100 / 0}$ \\
\hline Los-Angeles index, EN 1097-2 & - & 15 & 15 \\
\hline Polishing stone value, EN 1097-8 & - & 55 & 58 \\
\hline Aggregate abrasion value, EN 1097-9 & - & 10 & 10 \\
\hline Micro-Deval index, EN 1097-1 & - & 10 & 10 \\
\hline \multirow[t]{2}{*}{ Resistance to thermal shock, EN 1367-5 } & - & $\mathrm{I} \% 0.8$ & $\mathrm{I} \% 0.8$ \\
\hline & & $\mathrm{V}_{\mathrm{LA}} 3.4$ & $\mathrm{~V}_{\mathrm{LA}} 3.4$ \\
\hline Water absorption 24 h, EN 1097-6 & 1.0 & 1.0 & 1.0 \\
\hline Resistance to freezing and thawing, EN 1367-1 & - & $\mathrm{F}_{1}$ & $\mathrm{~F}_{1}$ \\
\hline Sand angularity index, EN 933-6 & $\mathrm{E}_{\mathrm{cs}} 38$ & - & - \\
\hline
\end{tabular}

Table A3. Properties of limestone aggregate used in "W" type mixes (results by the producer).

\begin{tabular}{|c|c|c|c|c|}
\hline Properties (Standard) & Limestone $0 / 2$ & Limestone $0 / 4$ & Limestone $2 / 8$ & Limestone 8/16 \\
\hline Aggregate size d/D (mm), EN 933-1 & $0 / 2$ & $0 / 4$ & $2 / 8$ & $8 / 16$ \\
\hline Aggregate distribution category (mm), EN 933-1 & $\mathrm{G}_{\mathrm{F}} 85$ & $\mathrm{G}_{\mathrm{A}} 90 / 15$ & $\mathrm{G}_{\mathrm{c}} 90 / 10$ & $\mathrm{G}_{\mathrm{c}} 90 / 20$ \\
\hline Aggregate tolerance category (mm), EN 933-1 & $\mathrm{G}_{\mathrm{TC}} 20$ & $\mathrm{G}_{\mathrm{TC}} 20$ & $\mathrm{G}_{20 / 17.5}$ & $\mathrm{G}_{20 / 15}$ \\
\hline Aggregate apparent density $\left(\mathrm{Mg} / \mathrm{m}^{3}\right)$, EN 1097-6 & $\rho_{\mathrm{a}} 2.71$ & $\rho_{\mathrm{a}} 2.71$ & $\rho_{\mathrm{a}} 2.71$ & $\rho_{\mathrm{a}} 2.71$ \\
\hline Agg. oven dried density $\left(\mathrm{Mg} / \mathrm{m}^{3}\right)$, EN 1097-6 & $\rho_{\text {rd }} 2.66$ & $\rho_{\text {rd }} 2.64$ & $\rho_{\text {rd }} 2.68$ & $\rho_{\text {rd }} 2.69$ \\
\hline $\begin{array}{l}\text { Agg. saturated surface dried dens. }\left(\mathrm{Mg} / \mathrm{m}^{3}\right), \mathrm{EN} \\
\qquad 1097-6\end{array}$ & $\rho_{\mathrm{ssd}} 2.68$ & $\rho_{\text {ssd }} 2.67$ & $\rho_{\text {ssd }} 2.69$ & $\rho_{\text {ssd }} 2.70$ \\
\hline Shape index (mass \%), EN 933-4 & - & - & $\mathrm{SI}_{25}$ & $\mathrm{SI}_{25}$ \\
\hline Flakiness index (mass \%), EN 933-3 & - & - & $\mathrm{FI}_{25}$ & $\mathrm{FI}_{25}$ \\
\hline Fines content (mass \%), EN 933-1 & 3 & 16 & 2 & 2 \\
\hline Fines quality (methylene blue value), EN 933-9 & - & $\mathrm{MB}_{\mathrm{f}} 10$ & - & - \\
\hline Bitumen affinity (rotating bottle test, \%) & - & - & $6 \mathrm{~h}: 65-90 \%$ & $6 \mathrm{~h}: 65-90 \%$ \\
\hline EN $12697-11$ & & & $24 \mathrm{~h}: 40-80 \%$ & $24 \mathrm{~h}: 40-80 \%$ \\
\hline $\begin{array}{l}\text { Percentage of crushed and broken surface (mass \%), } \\
\text { EN 933-5 }\end{array}$ & - & - & $\mathrm{C}_{100 / 0}$ & $\mathrm{C}_{100 / 0}$ \\
\hline Los-Angeles index, EN 1097-2 & - & - & 30 & 30 \\
\hline Polishing stone value, EN 1097-8 & - & - & 44 & 44 \\
\hline Aggregate abrasion value, EN 1097-9 & - & - & 15 & 15 \\
\hline Micro-Deval index, EN 1097-1 & - & - & 25 & 25 \\
\hline Resistance to thermal shock, EN 1367-5 & - & - & $\begin{array}{l}\mathrm{I} \% 0.2-1.0 \\
\mathrm{~V}_{\mathrm{LA}} 1-4\end{array}$ & $\begin{array}{l}\mathrm{I} \% 0.2-1.0 \\
\mathrm{~V}_{\mathrm{LA}} 1-4\end{array}$ \\
\hline Water absorption 24 h, EN 1097-6 & 1.0 & 1.0 & 1.0 & 1.0 \\
\hline Resistance to freezing and thawing, EN 1367-1 & - & - & $\mathrm{F}_{1}$ & $\mathrm{~F}_{1}$ \\
\hline Sand angularity index, EN 933-6 & $\mathrm{E}_{\mathrm{cs}} 30$ & $\mathrm{E}_{\mathrm{cs}} 30$ & - & - \\
\hline
\end{tabular}


Table A4. Asphalt mix dielectric measurements at $23{ }^{\circ} \mathrm{C}$, (sequential measurements at $\mathrm{f}=1.3,1.9,2.2,2.84,3.97$ and $5.23 \mathrm{GHz}), 95 \%$ Confidence Interval for the mean.

\begin{tabular}{|c|c|c|c|c|}
\hline Mix Designation & AC $8 \mathrm{G}$ & SMA 8 B & AC $16 \mathrm{~W}$ & AC 16 B \\
\hline Aggregate type & $\begin{array}{c}100 \% \\
\text { gabbro }\end{array}$ & $\begin{array}{l}100 \% \\
\text { basalt }\end{array}$ & $\begin{array}{c}100 \% \\
\text { limestone }\end{array}$ & $\begin{array}{l}100 \% \\
\text { basalt }\end{array}$ \\
\hline Dielectric constant $\varepsilon^{\prime}$ & $5.76-6.04$ & $6.45-6.74$ & $6.51-7.01$ & $6.60-7.22$ \\
\hline Dielectric loss factor $\varepsilon^{\prime \prime}$ & $0.031-0.044$ & $0.293-0.329$ & $0.033-0.035$ & $0.338-0.391$ \\
\hline
\end{tabular}

Table A5. Basic bitumen characteristics.

\begin{tabular}{ccc}
\hline Bitumen Characteristic & PMB 45/80-55 & 35/50 \\
\hline Penetration $25^{\circ} \mathrm{C}, 0.1 \times$ mm, EN 1426 & 54 & 42 \\
Softening point, ${ }^{\circ} \mathrm{C}$, EN 1427 & 61.0 & 53.8 \\
Breaking point, ${ }^{\circ} \mathrm{C}$, EN 12593 & -24 & -16 \\
\hline
\end{tabular}

\section{References}

1. Buncher, M.; Rosenberger, C. Best Practices for Constructing and Specifying HMA Longitudinal Joints; Asphalt Institute: Lexington, KY, USA, 2012.

2. Chen, C.; Williams, R.C.; Ahmed EI., T.; Lee, H.D.; Schram, S. Quality control/quality assurance testing for longitudinal joint density and segregation of asphalt mixtures. Constr. Build. Mater. 2013, 47, 80-85. [CrossRef]

3. Zofka, A.; Braham, A. Comparison of Low-Temperature Field Performance and Laboratory Testing of 10 Test Sections in the Midwestern United States. Transp. Res. Rec. J. Transp. Res. Board 2009, 2127, 107-114. [CrossRef]

4. Montepara, A.; Santagata, E.; Tosi, G. Photochemical degradation of pure bitumen by U.V. radiation. In Proceedings of the Eurasphalt \& Eurobitume Congress, Strasbourg, France, 7-10 May 1996; European Asphalt Pavement Association \& Eurobitume: Strasbourg, France, 1996; p. 13.

5. Maliszewski, M.; Zofka, A.; Maliszewska, D.; Sybilski, D. Asphalt Mixture Sensitivity to Water and Frost. In 8th RILEM International Symposium on Testing and Characterization of Sustainable and Innovative Bituminous Materials; Springer: Berlin/Heidelberg, Germany, 2016; Volume 11, pp. 177-188.

6. Mieczkowski, P. Securing cracks and expansion joints in the technology of hot-poured road repair compounds. Part 1. Classification and properties of compounds. Izolacje 2012, 17, 78-85.

7. Kandhal, P.; Mallick, R. Study of Longitudinal-Joint Construction Techniques in Hot-Mix Asphalt Pavements. Transp. Res. Rec. J. Transp. Res. Board 1996, 1543, 106-112. [CrossRef]

8. Zofka, A.; Mahoney, J.; Zinke, S.; Shaffer, G. Comparison of Butt and Notched Wedge Longitudinal Joints Constructed in Connecticut. In Proceedings of the ASCE's 2008 Airfield \& Highway Pavements Conference, Bellevue, WA, USA, 15-18 October 2008; pp. 258-262.

9. Williams, S.G. HMA Longitudinal Joint Evaluation and Construction Final Report; University of Arkansas: Fayetteville, AR, USA, 2011.

10. Kieswetter, B. Solving the Biggest Problem in Asphalt Paving. Available online: http://www.heavyequipmentguide.ca/article/ 24591/solving-the-biggest-problem-in-asphalt-paving (accessed on 8 April 2017).

11. Bueno, M.; Arraigada, M.; Partl, M.N. Induction heating technology for improving compaction of asphalt joints. Int. J. Pavement Eng. 2020, 21, 1532-1540. [CrossRef]

12. Akpinar, M.V.; Hossain, M. Longitudinal Joint Construction for Hot Mix Asphalt Pavements; Kansas State University: Manhattan, KS, USA, 2004.

13. Zanko, L. Evaluate and Develop Innovative Pavement Repair and Patching: Taconite-based Repair Options; University of Minnesota Duluth: Duluth, MN, USA, 2016.

14. Maliszewski, M. Zastosowanie Mikrofal Podczas Wykonywania i Naprawy Nawierzchni Asfaltowej (Application of Microwave Technology for Construction and Repair of Asphalt Pavements, PL), 1st ed.; Kiljan-Walerzak, J., Ed.; Instytut Badawczy Dróg i Mostów: Warszawa, Poland, 2020; ISBN 978-83-89252-34-0.

15. Maxwell, J.C. A Dynamical Theory of the Electromagnetic Field. Philos. Trans. R. Soc. Lond. 1865, 155, 459-512. [CrossRef]

16. Reitz, J.R.; Milford, F.J. Foundations of Electromagnetic Theory; Addison-Wesley: Reading, MA, USA, 1960.

17. Jackson, J.D. Classical Electrodynamics; John Wiley \& Sons: New York, NY, USA, 1962; ISBN 0-471-43131-1.

18. Mingos, D.M.P. Theoretical Aspects of Microwave Dielectric Heating. In Microwave Assisted Organic Synthesis; Blackwell Publishing Ltd.: Oxford, UK, 2009; pp. 1-22, ISBN 9781405175906.

19. Jones, D.; Lelyveld, T.; Mavrofidis, S. Microwave heating applications in environmental engineering-A review. Resour. Conserv. 2002, 34, 75-90. [CrossRef] 
20. Angoy, A.; Brianceau, S.; Chabrier, F.; Ginisty, P.; Jomaa, W.; Rochas, J.-F.; Sommier, A.; Valat, M. Microwave technology for food applications. Green Food Process. Tech. 2019, 455-498. [CrossRef]

21. Gulisano, F.; Gallego, J. Microwave heating of asphalt paving materials: Principles, current status and next steps. Constr. Build. Mater. 2021, 278, 121993. [CrossRef]

22. Al-Ohaly, A.A.; Terrel, R.L. Effect of microwave heating on adhesion and moisture damage of asphalt mixtures. Transp. Res. Rec. 1988, 1171, 27-36.

23. Terrel, R.L.; Hicks, R.G.; Ca, C.; Hall, L. Viability of Hot In-Place Recycling as a Pavement Preservation Strategy Report Number: CP2C-2008-106; California Pavement Preservation Center, CSU: Chico, CA, USA, 2008.

24. Zhu, S.Q.; Shi, J.F.; Hao, F. Research on the Pavement Performance of Recycled Asphalt Mixture Processed by Microwave. Adv. Mater. Res. 2010, 148-149, 987-993. [CrossRef]

25. Mitchell, M.R.; Link, R.E.; Wang, H.; Hao, P.; Xue, L. Laboratory Evaluation of Microwave Heating Method for Hot In-Place Recycling. J. Test. Eval. 2011, 39, 103122. [CrossRef]

26. Benedetto, A.; Calvi, A. A pilot study on microwave heating for production and recycling of road pavement materials. Constr. Build. Mater. 2013, 44, 351-359. [CrossRef]

27. Gallego, J.; del Val, M.A.; Contreras, V.; Páez, A. Heating asphalt mixtures with microwaves to promote self-healing. Constr. Build. Mater. 2013, 42, 1-4. [CrossRef]

28. Norambuena-Contreras, J.; Gonzalez-Torre, I. Influence of the Microwave Heating Time on the Self-Healing Properties of Asphalt Mixtures. Appl. Sci. 2017, 7, 1076. [CrossRef]

29. Norambuena-Contreras, J.; Garcia, A. Self-healing of asphalt mixture by microwave and induction heating. Mater. Des. 2016, 106, 404-414. [CrossRef]

30. Sun, Y.; Wu, S.; Liu, Q.; Li, B.; Fang, H.; Ye, Q. The healing properties of asphalt mixtures suffered moisture damage. Constr. Build. Mater. 2016, 127, 418-424. [CrossRef]

31. Liu, Q.; Chen, C.; Li, B.; Sun, Y.; Li, H. Heating Characteristics and Induced Healing Efficiencies of Asphalt Mixture via Induction and Microwave Heating. Materials 2018, 11, 913. [CrossRef]

32. Bhattacharya, M.; Basak, T.; Senagala, R. A comprehensive theoretical analysis for the effect of microwave heating on the progress of a first order endothermic reaction. Chem. Eng. Sci. 2011, 66, 5832-5851. [CrossRef]

33. Wang, H.; Zhang, Y.; Zhang, Y.; Feng, S.; Lu, G.; Cao, L. Laboratory and Numerical Investigation of Microwave Heating Properties of Asphalt Mixture. Materials 2019, 12, 146. [CrossRef]

34. Sun, Y.H.; Liu, Q.T.; Wu, S.P.; Shang, F. Microwave Heating of Steel Slag Asphalt Mixture. Key Eng. Mater. 2014, 599, 193-197. [CrossRef]

35. Wang, Z.; Xu, C.; Wang, S.; Gao, J.; Ai, T. Utilization of magnetite tailings as aggregates in asphalt mixtures. Constr. Build. Mater. 2016, 114, 392-399. [CrossRef]

36. Liu, W.; Miao, P.; Wang, S. Heating characteristics of microwave-absorbing asphalt mixture. In Proceedings of the Green Building, Environment, Energy and Civil Engineering, Hong Kong, China, 26-27 April 2016; Kao, J., Sung, W., Eds.; Taylor \& Francis Group: London, UK, 2016; pp. 163-167.

37. Lou, B.; Liu, Z.; Sha, A.; Jia, M.; Li, Y. Microwave Absorption Ability of Steel Slag and Road Performance of Asphalt Mixtures Incorporating Steel Slag. Materials 2020, 13, 663. [CrossRef]

38. Pérez, I.; Agzenai, Y.; Pozuelo, J.; Sanz, J.; Baselga, J.; García, A.; Pérez, V. Self-healing of asphalt mixes, containing conductive modified bitumen, using microwave heating. In Proceedings of the 6th Eurasphalt \& Eurobitume Congress, Prague, Czech Republic, 1-3 June 2016; Czech Technical University in Prague: Prague, Czech Republic, 2016.

39. Norambuena-Contreras, J.; Serpell, R.; Valdés Vidal, G.; González, A.; Schlangen, E. Effect of fibres addition on the physical and mechanical properties of asphalt mixtures with crack-healing purposes by microwave radiation. Constr. Build. Mater. 2016, 127, 369-382. [CrossRef]

40. Wang, Z.; Dai, Q.; Porter, D.; You, Z. Investigation of microwave healing performance of electrically conductive carbon fiber modified asphalt mixture beams. Constr. Build. Mater. 2016, 126, 1012-1019. [CrossRef]

41. Gallego, J.; Del Val, M.A.; Contreras, V.; Páez, A. Use of additives to improve the capacity of bituminous mixtures to be heated by means of microwaves. Mater. Constr. 2017, 67, 110. [CrossRef]

42. Zhu, X.; Fan, Y.; Yu, Y.; Gilabert, F.A. Crack propagation and microwave healing of Ferrite-filled asphalt mixes based on image correlation observations. Constr. Build. Mater. 2020, 262, 119978. [CrossRef]

43. Salski, B.; Olszewska-Placha, M.; Karpisz, T.; Rudnicki, J.; Gwarek, W.; Maliszewski, M.; Zofka, A.; Skulski, J. Microwave Applicator for Thermal Treatment of Bituminous Surfaces. IEEE Trans. Microw. Theory Tech. 2017, 65, 3419-3427. [CrossRef]

44. Maliszewski, M.; Maliszewska, D.; Zofka, A.; Bańkowski, W.; Gajewski, M.; Horodecka, R.; Mirski, K.; Sybilski, D. The Development of Innovative Microwave-Assisted Thermal Bonding of Asphalt Pavement-NGAM; Contract No. PBS2/B3/19/2013; National Centre for Research and Development: Warsaw, Poland, 2016.

45. Bishara, S.W.; McReynolds, R.L.; Mahoney, D.; Robertson, R.E. Rapid and Simple Method for Binder Oxidative Aging Report Number KS-99-5; Kansas Department of Transportation: Topeka, KS, USA, 1999.

46. PN-EN 12697-23:2017-12. Bituminous Mixtures—Test Methods—Part 23: Determination of the Indirect Tensile Strength of Bituminous Specimens; PKN: Warsaw, Poland, 2017. 
47. Chong, K.P.; Kuruppu, M.D. New specimen for fracture toughness determination for rock and other materials. Int. J. Fract. 1984, 26, 59-62. [CrossRef]

48. PN-EN 12697-46:2012. Bituminous Mixtures-Test Methods_Part 46: Low Temperature Cracking and Properties by Uniaxial Tension Tests; PKN: Warsaw, Poland, 2012.

49. Allen, R.G.; Little, D.N.; Bhasin, A.; Glover, C.J. The effects of chemical composition on asphalt microstructure and their association to pavement performance. Int. J. Pavement Eng. 2014, 15, 9-22. [CrossRef]

50. Anderson, R.M.; King, G.N.; Hanson, D.I.; Blankenship, P.B. Evaluation of the Relationship between Asphalt Binder Properties and Non-Load Related Cracking. Asph. Paving Technol. 2011, 615-663. 